\title{
Potential roles for prions and protein-only inheritance in cancer
}

\author{
Antony $\mathrm{H}^{* 1}$, Wiegmans $\mathrm{AP}^{*^{2}}$, Wei $\mathrm{MQ}^{1}$, Chernoff $\mathrm{YO}^{3}$, Khanna $\mathrm{KK}^{2}$, and Munn $\mathrm{AL}^{\S 1}$. \\ ${ }^{1}$ School of Medical Science and Molecular Basis of Disease Programme, Griffith Health \\ Institute, Griffith University (Gold Coast), Southport, Queensland, Australia. \\ ${ }^{2}$ Signal Transduction Laboratory, Queensland Institute of Medical Research, Brisbane, \\ Queensland, Australia. \\ ${ }^{3}$ School of Biology, Georgia Institute of Technology, Atlanta, Georgia 30332-0230, USA.
}

*These authors made an equal contribution.

$\S$ Corresponding author: Dr. Alan L Munn, School of Medical Science and Molecular Basis of Disease Programme, Griffith Health Institute, Griffith University (Gold Coast), Southport, Queensland, Australia. Phone: +61-7-55529307 Fax: +61-7-55528908 Email: a.munn@griffith.edu.au 


\begin{abstract}
Inherited mutations are known to cause familial cancers. However, the cause of sporadic cancers, which likely represent the majority of cancers, is yet to be elucidated. Sporadic cancers contain somatic mutations (including oncogenic mutations), however, the origin of these mutations is unclear. An intriguing possibility is that a stable alteration occurs in somatic cells prior to oncogenic mutations and promotes the subsequent accumulation of oncogenic mutations. This review explores the possible role of prions and protein-only inheritance in cancer. Genetic studies using lower eukaryotes, primarily yeast, have identified a large number of proteins as prions that confer dominant phenotypes with cytoplasmic (non-Mendelian) inheritance. Many of these have mammalian functional homologs. The human prion protein $(\mathrm{PrP})$ is known to cause neurodegenerative diseases and has now been found to be up-regulated in multiple cancers. $\operatorname{PrP}$ expression in cancer cells contributes to cancer progression and resistance to various cancer therapies. Epigenetic changes in gene expression and hyper-activation of MAP kinase (MAPK) signalling, processes that in lower eukaryotes are affected by prions, play important roles in oncogenesis in humans. Prion phenomena in yeast appear to be influenced by stresses and there is considerable evidence for association of some amyloids with biologically positive functions. This suggests that if protein-only somatic inheritance exists in mammalian cells, it might contribute to cancer phenotypes. Here we highlight evidence in the literature for an involvement of prion or prion-like mechanisms in cancer and how they may in the future be viewed as diagnostic markers and potential therapeutic targets.
\end{abstract}

Keywords: drug resistance, exosomes, genetic instability, heterogeneity, hyperthermia, metastasis 


\section{Introduction}

Familial cancers (i.e. heritable within family pedigrees) can be caused by germ line mutations. However, familial cancers account for only a small portion of the total cancer incidence; the majority of cancer incidence is sporadic (i.e. does not appear to conform to a clear genetic inheritance pattern) [1-2]. The cellular transformations that cause sporadic cancers are less well understood. Oncogenic mutations accumulate at the somatic level in sporadic cancers; however, the cellular mechanisms that generate these oncogenic mutations remain unclear [1]. Prions and protein-only inheritance could provide a potential explanation for sporadic cancers and the generation of oncogenic mutations at high frequencies at the somatic level. Prions are popularly known as the causative agents of neurodegenerative diseases in animals including humans, namely the transmissible spongiform encephalopathies (TSEs or prion diseases) [3-5]. Prions are proteins that have undergone a change of function via a stable and inheritable alteration in tertiary structure (e.g. switching to an amyloid-rich conformation). The change in protein structure impacts on cellular function and can result in cellular phenotypes independent of any change in DNA. The capability to transmit the change of function and tertiary structure to other copies of the same protein via protein-protein interactions defines prions as infectious agents and is mechanistically known as "protein-only inheritance". The altered phenotypes that result from protein-only inheritance may mimic those caused by genetic mutation; however, unlike mutations in nuclear genes, prions are non-chromosomal elements with cytoplasmic inheritance [6-8].

In this article, we use the word 'prion' to denote the infectious entity and 'prion proteins' to denote proteins that are known to form prions, except for the human Prion Protein (PrP). Since the conformational state of PrP (i.e. whether prion or not) is not known for all the contexts cited below, we have used $\operatorname{PrP}$ to refer to the human prion protein and where known, we use $\operatorname{PrP}^{\mathrm{C}}$ and $\operatorname{PrP}^{\mathrm{Sc}}$ to refer to the normal (uninfected) and prion/infectious isoforms, respectively.

The human cellular protein $\operatorname{PrP}^{\mathrm{C}}$ is expressed at high levels endogenously in the brain and is susceptible to infection by the $\mathrm{PrP}^{\mathrm{Sc}}$ prion resulting in protein fold changes, amyloid formation and neuronal disease. However, PrP has also been detected in other tissues [9]. Expression in organs as diverse as lymphoid cells, lung, heart, kidney, gastrointestinal tract, muscle, and mammary glands suggests that PrP may regulate multiple metabolic systems. Prion-mediated changes in protein function may represent initiating events that promote "hallmarks of cancer", including selfsufficiency in growth signals, insensitivity to anti-growth signals, tissue invasion and metastasis, limitless replicative potential and inhibition of apoptosis [10]. PrP is highly expressed at the protein 
level in several cancers including: breast cancer [11], gastric cancer [12], colon cancer [13], pancreatic cancer [14-15] and prostate cancer [16] (see Table 1). Expression microarray studies have also revealed over-expression of the PrP-encoding gene (PRNP) at the transcriptional level in human colorectal cancer [17] and pancreatic cancer cell lines [18]. Generally, over-expression of PrP induces inherent resistance to cancer therapeutics while repression or knockdown of $\operatorname{PrP}$ induces sensitization to cancer therapeutics [9]. An intriguing possibility, as yet untested, is whether infection of $\operatorname{PrP}^{\mathrm{C}}$ by the $\operatorname{PrP}^{\mathrm{Sc}}$ prion also plays a role in resistance to cancer therapeutics. Here, we discuss the properties and behaviors of prions and the mechanism of prion-mediated protein-only inheritance. Further, we examine the role of PrP in tumor resistance to chemotherapy mediated by several mechanisms: PrP interactions with chaperones, $\operatorname{PrP}$ anti-apoptotic activity and enhanced metastatic potential of cells expressing high levels of PrP.

\section{Properties and behavior of prions}

\section{Prion Diseases}

The term "prion” is derived from "proteinaceous infection particle” and was first used to refer to the sheep scrapie pathogen. According to the prion concept, first formulated by S. Prusiner in the late $20^{\text {th }}$ century, the prion protein has two distinct structural conformations that contain the same amino acid content and sequence [3-4]. The cellular form $\mathrm{PrP}^{\mathrm{C}}$ undergoes a post-translational switch of 3D protein conformation from a soluble, globular, and proteinase-sensitive form to an insoluble, fibrous, predominantly $\beta$-sheet-containing and protease-resistant amyloid form with altered function [19]. The pathogenic form $\operatorname{PrP}^{\mathrm{Sc}}$ is an infectious agent that is resistant to heating; proteinase $\mathrm{K}$ digestion; denaturation by urea, chaotropic salts, or detergents such as sodium dodecyl-sulphate (SDS); and DNA-damaging agents such as radiation. Its reduced turnover causes it to accumulate in diseased tissues (reviewed in [20,6]). Known prion diseases include the mammalian spongiform encephalopathies such as bovine spongiform encephalopathy (BSE) or mad cow disease, chronic wasting disease (CWD), transmissible mink encephalopathy, feline spongiform encephalopathy, ungulate spongiform encephalopathy and sheep scrapie, and some of the human neurodegenerative diseases including Creutzfeldt-Jakob disease (CJD), variant Creutzfeldt-Jakob Disease (vCJD), Gerstmann-Straussler-Scheinker syndrome (GSS), familial fatal insomnia (FI) and kuru. All these diseases are characterized by long incubation periods, characteristic spongiform changes to the tissue of the brain associated with neuronal loss, and a failure to induce inflammatory responses [5]. Few disease cases are attributable to acquired $\mathrm{PrP}^{\mathrm{Sc}}$ prion $(<1 \%)$. In comparison, the great majority of disease cases (85\%) are attributable to spontaneous conformational conversion of $\operatorname{PrP}^{\mathrm{C}}$ to the $\mathrm{PrP}^{\mathrm{Sc}}$ prion in affected individuals. The remainder of disease cases are not caused by prion infection 
of $\operatorname{PrP}^{\mathrm{C}}$, but rather to mutations in the gene encoding $\operatorname{PrP}^{\mathrm{C}}$ (PRNP) (15\%) (reviewed in [8]). Prion diseases are described as conformational diseases, where an alteration in 3D structure of particular proteins results in changes in cell physiology [8]. Regardless of the origin of the prion (i.e. spontaneously arising or transmitted), all known prion diseases of animals are infectious and fatal.

\section{Yeast Prions}

Prions and protein-only inheritance have been extensively studied in lower eukaryotes (e.g. yeast). Changes in yeast phenotypes are brought about by the structural conversion of certain cellular proteins to amyloid prions. The amyloid prion form then acts to ensure that all other copies of the same polypeptide are also switched to the amyloid prion form and are inherited by progeny cells. Hence, the amyloid forms of these yeast proteins are referred to as "yeast prions". Yeast prions are not related to diseases instead they have an adaptive significance and underlie the inheritance of phenotypic traits (reviewed in [6-8]).

Of the $>6,000$ proteins encoded by the yeast genome, at least 25 have been shown to contain domains that are able to switch to a self-perpetuating amyloid form when fused to other proteins (prion-forming domains, PrDs) [21], and at least 9 of these proteins are proven to be capable of maintaining the prion state in their native form (see [22]). The actual number of prion-forming proteins in the yeast proteome could be much larger, as searches that identified the currently known PrDs were heavily biased towards the amino acid composition of already known yeast PrDs. PrDs are the structurally autonomous domains of amyloid prions that allow conformational duality and can be transferred as modules to other proteins to create novel prions [7,23]. Most of the yeast prions are self-propagating amyloids. Prion states are typically designated as $\left[\mathrm{PSI}^{+}\right],\left[\mathrm{PIN}^{+}\right]$, $\left[\mathrm{SWI}^{+}\right],\left[\mathrm{OCT}^{+}\right]$, with an exception of [URE3] for which a “" and italics are not used (square bracket enclosure are used to indicate cytoplasmically inherited genetic determinants in yeast and capital letters indicate dominance). In the prion state, the above-mentioned prions form amyloidal aggregates, whilst some (e.g. $\left[\mathrm{PSI}^{+}\right]$and [URE3]) also show resistance to proteinase $\mathrm{K}$ digestion. These protein-based prion states are dominant, inherited in a non-Mendelian fashion and transmitted by cytoplasmic infection (cytoduction). PrDs of proteins Sup35, Ure2 and Rnq1, responsible for $\left[\mathrm{PSI}^{+}\right]$, [URE3] and $\left[\mathrm{PIN}^{+}\right]$prions respectively, are proven to form amyloid fibrils in vitro, that are capable of transmitting the prion state through in vitro "infection" [24-26]. Analogous to the $\operatorname{PrP}^{\mathrm{Sc}}$ strains seen in $\mathrm{vCJD}$, yeast prions also exhibit strain diversity, where the strains represent different prion conformations that are known in yeast as variants [26-27]. Variants of $\left[\mathrm{PSI}^{+}\right]$and $\left[\mathrm{PIN}^{+}\right]$will be discussed below. 
Of the yeast prions, $\left[\mathrm{PSI}^{+}\right][28]$ is probably the most extensively studied. It is the prion state of the translation termination factor called eRF3, or (in yeast) Sup35p (see [7,6] for reviews). Conversion of Sup35p to the $\left[\mathrm{PSI}^{+}\right]$prion causes decreased function of Sup35p i.e. defective translation termination. Hence, the prion form causes read-through of mRNA termination codons. It was hypothesized that $\left[\mathrm{PSI}^{+}\right]$may produce C-terminally extended and functionally altered polypeptides that may increase phenotypic plasticity and therefore, the ability of yeast to survive adverse environmental conditions [29]. This can be considered analogous to "cancer-like” transformation. The read-through of premature termination codons generated by mutations (a.k.a. nonsense mutations) occurs in $\left[\mathrm{PSI}^{+}\right]$strains and is used for $\left[\mathrm{PSI}^{+}\right]$detection $[7,6]$. This phenomenon is an example of nonsense-suppression. Of note, the prion-forming ability of Sup35p is conserved through several hundred million years of evolution [30,7]. However, $\left[\mathrm{PSI}^{+}\right]$prion is not found in the natural or industrial isolates of yeast [30-32], and some variants of [PSI ${ }^{+}$are clearly cytotoxic [33]. Sup35p, as other yeast prion proteins, contains a PrD located at the N-terminus. PrDs of Sup35p and other yeast prions have unusual amino acid composition, which is enriched in polar residues and depleted of charged residues, promoting a disordered molten-globule-like protein conformation that favors the formation of amyloid-nucleating contacts [22]. PrDs determine the infectious properties of prion proteins and are sufficient for prionization [7].

[URE3] is the prion state of the Ure2p, a negative regulator of genes involved in nitrogen catabolism [34-35]. [URE3] allows enhanced uptake of alternative nitrogen sources (including ureidosuccinate) in both poor and optimal nitrogen environments due to the partial loss of Ure2p function. The PrD of Ure2p is located in the N-terminus of the protein (reviewed in [8]. [GAR ${ }^{+}$is another yeast prion related to metabolism. Normally, in the presence of glucose (even in trace amounts), yeast suppress utilization of any alternative carbon source. However, $\left[G A R^{+}\right]$allows yeast cells to be resistant to this glucose-associated repression [36].

$\left[\mathrm{PIN}^{+}\right]$(derived from $\left[\underline{P S I^{+}}\right]$inducibility) is the prion state of Rnq1p, a protein rich in asparagine (N) and glutamine (Q) which facilitates de novo formation (but not propagation) of other amyloid prions, for example $\left[\mathrm{PSI}^{+}\right]$[37]. It induces $\left[\mathrm{PSI}^{+}\right]$formation upon Sup35p overproduction, possibly by seeding its polymerization [38]. $\left[\mathrm{PIN}^{+}\right]$has variants that differ in the efficiency with which they induce $\left[\mathrm{PSI}^{+}\right][39]$.

It is worth noting that the list of about 200 yeast proteins that contain domains similar to PrDs of known yeast prions by amino acid composition is enriched for globally acting transcription factors like $\left[\mathrm{SWI}^{+}\right][40],\left[\mathrm{OCT}^{+}\right][41],\left[\mathrm{MOT3}^{+}\right][21],\left[\mathrm{ISP}^{+}\right]$[42], etc and RNA-binding proteins [21]. 
These observations imply that epigenetic switches based on prionization could regulate gene transcription at a global level thus altering metabolism and cell differentiation (discussed in $[22,43])$.

[Het-s] is an amyloid prion found in the filamentous fungus Podospora anserina [44] that has a $\operatorname{PrD}$ in the C-terminal region (218-289). Structural studies reveal the conformational transition of the normally flexible C-terminal tail into amyloid fibrils comprising of $4 \beta$-strands per fold [45]. Unlike the other amyloid prions discussed above, the [Het-s] prion does not cause functional inactivation of the wild type protein, instead it can cause a reaction known as vegetative incompatibility; this is a genetic system that controls the ability of two fungal strains to come together via a process known as anastomosis. Of the nine het loci that regulate this parasexual process, incompatibility of het-s loci due to the prion form [Het-s] limits heterokaryon formation and anastomosis, thus preventing harmful hyphal fusions in fungi [46]. [Het-s] forms insoluble aggregates and is resistant to digestion with proteinase K. Like other amyloid prions, [Het-s] protein forms amyloid fibrils in vitro that stably transmit the prion state through in vitro "infection" [47].

A new class of fungal prion-like phenomena includes self-activating proenzyme prions that are propagated due to self-sustainable modifications rather than in amyloid forms, e.g. [ $\beta$ ] of Saccharomyces cerevisiae [48] and [C] of Podospora anserina [49]. Here, the prion protein activates its own inactive proenzyme precursor [6]. The [ $\beta]$ prion is associated with a gain-offunction phenotype via activation of the pro-proteinase B (precursor) form of vacuolar proteinase $B$ by the mature proteinase B (prion) form. The activated proteinase B state is transmitted by cytoduction and demonstrates all other properties of a prion [6]. The prion-like phenotype designated as [C] is characterized by slow hyphal growth and dark pigmentation. It is thought to be the prion form of Mitogen-Activated Protein Kinase Kinase Kinase (MAPKKK) as it causes hyperactivation of MAPKKK such that it becomes independent of upstream signals [49]. This is again “cancer-like” behavior [50].

It is also notable that de novo formation of yeast prions is increased by some stresses [51-52]. Prion propagation is controlled by an Hsp machinery (for reviews, see [53-54]), and heat shock destabilizes some variants of $\left[\mathrm{PSI}^{+}\right]$prion, apparently due to alterations in chaperone balance leading to improper segregation in cell divisions [55]. It was proposed that some prions may arise as by-products of the protein complexes formed with the purpose of protecting certain proteins from unfavorable conditions [53]. 


\section{Mammalian Prions}

As shown in Table 2, mammalian prions share many of the same characteristics when compared to yeast prions. Although the PRNP gene that encodes PrP is present in the genome of all mammals, birds, and fish, $\operatorname{PrP}$ is a non-essential protein. Mice devoid of $\operatorname{PrP}$ are capable of normal development, behavior, and reproduction [56]. Furthermore, animals homozygous for a disruption of the PRNP gene are found to be resistant to scrapie [57]. Studies have also found an "interspecies barrier" that restricts transmission of prions between unrelated species such as that seen between different Fungi [6-7,58]. This barrier results in distinct incubation periods and patterns of neuropathology in prion-mediated disease in different animals [6]. These barriers are introduced by mutations in the PrD of prions (reviewed in [6-7,58]). The PrD of mammalian PrP resides in the Nterminus and is slightly different to most other prions. While residues 108-124 are important for the conformational conversion of $\operatorname{PrP}^{\mathrm{C}}$ to $\mathrm{PrP}^{\mathrm{Sc}}$ [59], there is an octapeptide repeat region between residues 52-90 that modulates prion assembly kinetics [60]. Similar oligopeptide repeats in yeast Sup35p serve to stabilize prion propagation of yeast $\left[\mathrm{PSI}^{+}\right]$[61]. Prion variability, a.k.a. prion strain diversity, is yet another feature of this protein family and it reflects the ability of the prion protein to acquire and/or spontaneously adopt different 3D protein conformations, which are stably maintained and propagated in vivo e.g. vCJD $[4,62]$. The strain diversity depends primarily on the amino acid sequence of $\operatorname{PrP}$ as this defines the set of possible 3D conformations that the protein can adopt. Variability may also depend on PrP glycosylation patterns [63]. The human prion protein has two sites of N-glycosylation, residues 181 and 197. Glycoforms have been identified by Western blotting that exhibit differential glycosylation of these sites. The proportion of these glycoforms varies between prion proteins. For example, a higher amount of diglycosylated PrP (protease resistant form-type 2B) distinguishes vCJD from sCJD patients [63]. Interestingly, a recent study has shown that the anti-apoptotic activity of PrP in oral and colon cancer cells depends on its glycosylation [64].

Prions are not exclusive to Fungi or mammalian PrP. Many mammalian proteins other than PrP, may also have the ability to undergo spontaneous conformational conversion to a prion form based on the fact that they fulfil various criteria established by studies of yeast prions (discussed above). In fact, it was recently discovered that the functional RNA-binding form of the neuronal isoform of the translational regulator CPEB (cytoplasmic polyadenylation element binding) protein in the sea slug Aplysia californica shows prion patterns in non-native systems and aggregation in the native system. CPEB forms dominant self-perpetuating prion-like multimers [65-66]. Isoforms of CPEB protein are also found in mice (CPEB-3 and CPEB-4) and humans (CPEB-1). The mouse isoforms have been reported to form aggregates in neuroblastoma cells [67], while the human isoform 
remains untested. All of the CPEB proteins have an N-terminal domain resembling a PrD. ApCPEB and CPEB-3 contain prion-like glutamine-rich (Q-rich) domains (discussed below) which represent $48 \%$ and $18 \%$ of the full length proteins, respectively [8,66-67]. In contrast, CPEB-4 is rich in proline and bears sequence motifs similar to that of $\operatorname{PrP}^{\mathrm{Sc}}[8,67]$. Reminiscent of other yeast and mammalian prions, the presumed CPEB prion also exhibits strain diversity with distinct activity states [68]. It is important to note that, unlike the disease causing $\operatorname{PrP}^{\mathrm{Sc}}$, the proposed prion form of CPEB serves to function in memory formation. Indeed, the prion-like mechanism in CPEB allows generation of stable, self-perpetuating biochemical memories or stable synapses in the brain through distinct prion-like strains [68]. Some studies with mice suggest the intriguing possibility that if CPEB can be infected by a prion, this may have the potential to alter the expression of tumor suppressors and thereby play a role in neuroblastoma, e.g. CPEB has been reported to regulate p53 mRNA translation and cellular senescence in human [69] and mouse [70] cell models. These studies clearly highlight the biological relevance and importance for prion-based protein function in higher eukaryotes and mammals.

Similar to the proposed CPEB prion, we hypothesize that many mammalian proteins may be susceptible to infection by amyloid prions that have yet to be identified. These susceptible mammalian proteins may include well-characterized proteins like, p53, a key tumor suppressor in vertebrates (detailed under "possible role for prions in metastasis"). Whether p53 is involved directly in the transformation of normal cells via a "prion-like” infectious mechanism is unlikely; however, there are certainly more mammalian “prion-like” proteins yet to be discovered.

\section{Prion Propagation and Induction Factors}

Propagation and induction of prions require multiple cis- and trans-acting factors.

1. Amino Acid Content: The ability of Sup35 or Ure2 protein to form a prion depends more on amino acid composition than on specific amino acid sequence; whereas the efficiency of prion transfer to an uninfected protein depends on a specific sequence (reviewed by [6]). The yeast proteins most susceptible to prion formation possess a glutamine- and asparagine-rich (Q/N-rich) domain [71-73]. This agrees with the observation that glutamine repeats are found in several aggregation-prone and amyloidogenic proteins associated with neurodegenerative diseases. Database analysis of protein structure shows a high percentage of RNA-binding proteins (RBPs) among proteins with QN-rich domains [21,74]. RBPs can associate with RNA as it leaves the nucleus and act as "RNA chaperones" to promote formation of RNA-protein complexes [75]. Therefore, if prionogenic RBPs bind to mRNA and act to regulate the efficiency of protein 
translation, prions may potentially influence not only the 3D-structure of proteins, but also protein expression levels. In addition, nucleic acids are also believed to be important players in helping trigger conversion of $\operatorname{PrP}^{\mathrm{C}}$ to $\operatorname{PrP}^{\mathrm{Sc}}$ and $\mathrm{PrP} /$ nucleic acid complexes have been proposed to act as catalysts to increase the rate of aggregation of prions and associated proteins [76-77]. Recent studies demonstrate that cytoplasmic PrP expression can induce the formation of large ribonucleoprotein particles and thereby also affect post-transcriptional regulation of protein expression [78]. Thus, prion infectivity may have a dual role of control in altering both protein function and expression contributing to cellular phenotypic changes.

Contrastingly, the C-terminal PrDs of human PrP (121-231aa) and yeast [Het-s] (218-289aa) are not QN-rich but can still propagate as prions [79]. While the $\mathrm{Q} / \mathrm{N}$-rich domain is important for prionization, an adjacent motif, the oligopeptide repeat, is required for the propagation and stable non-Mendelian inheritance of these aggregates [80]. For example, in Sup35p, the middle region (124-253aa) adjacent to the N-terminal PrD (1-123aa), which is enriched (42\%) in charged amino acids like lysine and glutamic acid, helps to stably maintain the prion form. Similarly, some regions in the C-terminus of Ure2p also influence the prion conversion of the N-terminal PrD [72]. In fact, it is observed that the $\mathrm{N}$-terminal region of $\mathrm{PrP}$ affects prion transformation and aggregation [81,59], while the number of oligopeptide repeats in $\operatorname{PrP}$ affected the probability of $\operatorname{PrP}^{\mathrm{Sc}}$ formation by modulating prion assembly kinetics [60,82].

2. Molecular chaperones: Despite the abundance of QN-rich proteins in yeast and mammals, only few form heritable aggregates. This is because prion inheritance requires both an aggregation sequence (such as the PrDs and oligopeptide repeats that are responsible for self-seeded growth) and an element that permits chaperone-dependent replication to ensure stable propagation of the infectious, aggregation-prone form [80]. Prion proteins associate with molecular chaperones that can regulate conformational conversion, such as Hsp104p in yeast $[54,83]$ and $\alpha \beta$-crystallin in mammals [84]. In both yeast and mammalian cells, molecular chaperones employ a highly conserved set of post-translational mechanisms to assist in protein folding and promote disaggregation by converting folded subunits into oligomeric structures. Chaperones inherently try to help stabilize protein folding; however, chaperone binding can also enhance protein aggregation via breaking off small clumps from the main mass of aggregated protein. This disaggregation of prion aggregates by molecular chaperones generates forms of the prion protein that can seed the protein polymerization mechanism underlying the prion propagation cycle [85-86]. The types of prion variant formed also depend on aggregate sensitivity to the severing activity of the chaperones [87-90]. Thus, physical interaction of prions and endogenous chaperones can result in more 
efficient and enhanced prion infectivity. This, combined with the known ability of prions to alter protein function and expression, is likely to result in significant changes in cellular phenotypes. This includes changes that enhance cellular survival or "cancer-like” phenotypes. This phenotype could be efficiently passed on in cell progeny and suggests a potential role for prions in the progression of a phenotype from cell to cell.

3. Actin cytoskeleton: Although much is known about prion propagation, the initial induction of prions from non-prion protein remains to be elucidated. It is thought that the de novo appearance of prions is predominantly induced by transient overproduction of $\mathrm{Q} / \mathrm{N}$-rich proteins (reviewed in [8]) or PrDs [23]; however, there are reports of similar interactions with non-Q/N-rich prions [67]. Prionization is influenced by interactions of yeast and mammalian prions with the cortical actin cytoskeleton and other membrane-associated cytoskeletal networks [91-95]. Alterations in the cortical actin cytoskeleton greatly reduce de novo prion induction and accumulation of prion aggregates [94]. A role of the cytoskeleton in the generation of prion aggregates is explained by a model in which cytoskeletal structures provide a scaffold for the generation of aggregate deposits, which in turn provide sites for prion protein accumulation and prion polymerization [94,96]. It has been shown that the short-lived stress-inducible actin cytoskeleton associated protein Lsb2 plays a role in this process [93]. Actin cytoskeleton disruption also destabilizes some variants of the [PSI $\left.{ }^{+}\right]$ prion [97], and a lack of Lsb2p increases the destabilizing effect of heat shock on a prion, pointing to the role of the actin cytoskeleton in prion maintenance (and possibly formation) during stresses [93]. As actin polymerization is also critical for cancer cell motility [98], the assembly of prion aggregates within actin-rich complexes suggests a potential role for prions in cancer cell migration and metastasis.

\section{Prions and Cancer}

\section{A Possible Role for Prions in Cancer}

There are several lines of evidence that support the possible involvement of prions in cancer (summarized in Table 3). Firstly, several types of cancer demonstrate over-expression of $\operatorname{PrP}$ (whether $\operatorname{PrP}^{\mathrm{C}}$ or $\operatorname{Prp}^{\mathrm{Sc}}$ was not tested) including: colorectal [13], gastric [99], breast [100] and glioblastoma [9]. This observation does not directly confirm a role for PrP in the establishment or progression of cancer; however, loss of over-expression of PrP does inhibit cancer cell growth, suggesting a requirement for PrP over-expression in rapid cell proliferation and/or enhanced survival. In gastric cancer, over-expression of PrP renders the cells resistant to adriamycin, while sensitivity is restored upon the knockdown of PrP [12]. Further, the expression of PrP in primary 
tumors has been assessed by immunohistochemistry in a series of 756 patients that were part of two randomized trials comparing anthracycline-based chemotherapy to no chemotherapy. The positive rate of PrP expression in breast cancer tissues was 15\% (113/756) and was positively correlated with cancers that were resistant to chemotherapy [11]. Whether the cancer phenotype is a result of PrP over-expression per se or whether PrP over-expression in a sub-population of cells simply confers an inherent survival advantage and therefore selection pressure on this sub-population of cells is yet to be determined.

Unlike mutations in nuclear genes, prions exhibit cytoplasmic inheritance. The altered cellular phenotypes caused by infection of gene products with prions precisely mimic those caused by mutations in the same genes. Some are loss-of-function phenotypes while others are gain-offunction phenotypes. However, unlike mutation of genes, the phenotypes are always dominant and their inheritance is cytoplasmic rather than nuclear. If cancer phenotypes are due in part to prions, they would also be expected to exhibit cytoplasmic inheritance. In this regard, it is interesting that at least one study has reported the cytoplasmic inheritance of cellular metastatic potential in cell culture models (detailed under “possible role for prions in metastasis”).

Cancers form by changes in regulation and expression of genes and subsequently proteins. Cancers that are heritable within family pedigrees may be due to germ line mutation such as in familial breast cancer, while those that are not, we speculate may be due to infection of the same or functionally related proteins with a prion. The frequency of spontaneous prion formation [89] is somewhat higher than that of spontaneous mutations [101]; but, interestingly, it is similar to the frequency with which spontaneous metastatic variants arise from clonal cancer cells (see the explanation for phenotypic heterogeneity under "possible role for prions in metastasis"). In part, this is due to the higher frequency of spontaneous conversion of amyloidogenic proteins to an amyloid prion form. All prion phenotypes arise (and revert) spontaneously with a frequency between $1 \times 10^{-5}$ [102] and $1 \times 10^{-7}$ [52] per cell per generation. As with mutation rates, the frequency at which cellular proteins undergo conformational conversion to prions can be artificially increased. The frequency of conformational conversion of cellular proteins to prions is strongly enhanced by exposure to environmental triggers such as oxidative stress or high salt concentrations [52]. Conversely, other stressors, e.g. UV radiation, can cause loss of $\left[\mathrm{PSI}^{+}\right]$, possibly via the induction of Hsp104 (discussed in [83]). For a rare event such as spontaneous mutation (incidence up to $1 \times 10^{-6}$ per cell per generation [101]) to affect both copies of a gene would be an exceedingly rare occurrence ( $1 \times 10^{-12}$ per cell per generation). However, phenotypes that arise from prions are dominant. Therefore, only one rare event (frequency of $1 \times 10^{-5}-1 \times 10^{-7}$ ) is required for the 
phenotype to arise irrespective of the gene copy number. Finally, the frequency of prion induction in yeast is also influenced by the very large number of proteins encoded in the genome (approximately 1 in 30) that are predicted to have the ability to spontaneously switch to an amyloid prion form [21].

Another line of support for the possible involvement of prions in cancer is the fact that while mutations and the phenotypes they cause are, by nature, stochastic, prions and the phenotypes they cause are not. A spontaneous mutation does not usually confer a selective growth advantage. It is as likely to be lethal or severely detrimental as it is to confer a selective advantage. In contrast, the ability of certain proteins to switch to amyloid prions is not stochastic. The frequency of prion induction and the types of prions that are induced are under the influence of environmental factors, i.e. by the type of stress the cells are exposed to [52]. The ability to induce prions was likely acquired during evolution to enhance the ability of cells to rapidly diversify and adapt. Interestingly, prion induction in yeast and/or other fungi has been shown to result in receptor-independent MAP kinase pathway signaling, to affect apoptosis induction proteins, to alter chromatin-remodelling proteins, and to inactivate global transcriptional regulators (see "yeast prions" discussed earlier). Receptor-independent growth factor signaling, altered global transcription patterns, and impairment of apoptosis are all phenotypes commonly associated with cancer cells [10].

\section{A Possible Role for Chaperones in Prion Switching in Cancer}

The main roles of heat shock proteins (HSPs) and chaperones are to prevent non-specific aggregation of denatured proteins and to assist in protein re-folding (renaturation). In contrast, prions or prion proteins promote the formation of insoluble protein aggregates. The potential interplay between the two classes of proteins provides a unique scenario that could potentially regulate cancer progression based on the assumption that prion proteins have a role in cancer. There are several links between heat shock proteins and $\operatorname{PrP}$ (whether $\operatorname{PrP}^{\mathrm{C}}$ or $\operatorname{Prp}^{\mathrm{Sc}}$ was not tested) and these are discussed below.

First, the heat shock protein $\alpha \beta$-crystallin interacts with $\operatorname{PrP}$ (Fig. 1). It binds to the highly disordered but functionally conserved N-terminal PrD of bovine $\operatorname{PrP}(\mathrm{BoPrP})$ [84]. This interaction could potentially prevent the conversion of the $\operatorname{PrP}^{\mathrm{C}}$ to $\operatorname{PrP}^{\mathrm{Sc}}$. However, at the same time, this sequesters $\alpha \beta$-crystallin chaperone activity and may reduce the access of other misfolded proteins to $\alpha \beta$-crystallin. This interference by $\operatorname{PrP}$ with the chaperoning function of $\alpha \beta$-crystallin may promote cancer. In support of this, $\alpha \beta$-crystallin has been observed to be downregulated in pancreatic carcinoma. Moreover, over-expression of $\alpha \beta$-crystallin in a pancreatic cell line retarded cell 
migration. This suggests that $\alpha \beta$-crystallin negatively regulates pancreatic carcinogenesis [103]. In this instance, $\operatorname{PrP}$ interaction with $\alpha \beta$-crystallin would result in the reduced availability of the chaperone to perform its function and promote cell migration and cancer.

Second, the promoter of the PRNP gene that encodes PrP contains two heat shock elements [104]. Heat shock elements are bound by transcription factors, including heat shock transcription factors, in response to cellular stress (including but not limited to heat) and induce enhanced expression of target genes. Experimental evidence for the regulation of $\operatorname{PrP}$ transcription by heat shock proteins comes from the finding that heat shock of human neuronal cells results in simultaneous induction of PrP and the heat shock protein 70 (HSP70) at both the mRNA and protein levels [104-105]. Thus, it is conceivable that induction of cellular stress responses could increase sequestration of HSPs (caused by a coordinated increase in PrP protein levels) and this may result in activation of pathways that promote cancer.

Third, the observation that over-expression of $\alpha \beta$-crystallin and $\operatorname{PrP}$ protein (whether $\operatorname{PrP}^{\mathrm{C}}$ or $\operatorname{Prp}^{\mathrm{Sc}}$ was not tested) has contrasting effects on cancer cell cycle progression. As part of SCF E3 ubiquitin ligase, $\alpha \beta$-crystallin induces the degradation of cyclin D1. Cyclin D1 is essential for cell cycle progression, so $\alpha \beta$-crystallin could potentially induce cell cycle arrest and thereby interfere with cancer progression. However, in contrast, PrP promotes G1/S transition via induction of cyclin D1 expression. The promoter of the cyclin D1 gene is activated by $\operatorname{PrP}$ in gene reporter assays, while knockdown of PrP via RNAi decreases cyclin D1 levels [9,106]. This supports a possible dual role for PrP in promoting cell cycle progression via activating transcription of cyclin D1 and interfering with $\alpha \beta$-crystallin-dependent turnover of cyclin D1 (Fig. 1). Notably, over-expression of PrP in the nucleus of breast cancer cells induces multinucleation, which is often seen in cancerous cells with cell cycle checkpoint defects (reviewed in [9]). Thus, over-expression of PrP may activate oncogenic pathways by simultaneous promotion of cell cycle progression and polyploidy.

\section{Anti-apoptotic Activity of PrP}

Inhibition of apoptosis is one of the hallmarks of cancer [10,107]. Intriguingly, $\operatorname{PrP}$ (whether $\operatorname{PrP}^{\mathrm{C}}$ or Prp ${ }^{\mathrm{Sc}}$ was not tested) displays anti-apoptotic/pro-survival activity. The underlying mechanism has not yet been fully elucidated; however, it does involve components of both the extrinsic and intrinsic apoptotic pathways.

The extrinsic pathway regulates response to external apoptotic signals detected by members of the tumor necrosis factor (TNF) receptor super family. Upon binding of their cognate ligand, these 
specialized pro-apoptotic cell surface receptors become activated and oligomerize within the membrane thus forming a complex known as the death inducing signaling complex (DISC). DISC then initiates apoptosis via the activation of caspases. Cells over-expressing PrP are known to be resistant to the induction of apoptosis initiated via the TNF-related apoptosis inducing ligand receptor (TRAIL-R/DR4/DR5) and TNF [100].

The intrinsic apoptotic pathway regulates response to internal apoptotic signals and is mediated by the BH3-only pro-apoptotic proteins. BH3-only proteins antagonize the protective activity of Bcl-2 pro-survival family members at the mitochondria and activate pro-apoptotic Bax/Bak, which then induce mitochondrial outer membrane permeabilization (MOMP) and finally lead to the induction of the caspase cascade (Fig. 1). PrP shares significant amino acid sequence similarity with the Bcl-2 homology domain 2 (BH2) contained in both the pro-survival Bcl-2 family members and the proapoptotic Bax and Bak members of the Bcl-2 family. In fact, PrP is found to inhibit the conformational switch required for activation of the multi-domain pro-apoptotic protein Bax [108], thereby disrupting the formation of higher-order Bax oligomers and MOMP that are required to mediate apoptosis (Fig. 1) [109]. Yeast two-hybrid assays also show that PrP is able to bind Bcl-2 in a similar way to Bax [110]. Taken together, this supports the hypothesis that PrP regulates Bax via direct interaction with Bcl-2 [111]. Interestingly, knockdown of PrP resulted in decreased Bcl-2 expression, while other pro-survival Bcl-2 family members like Bcl-xL and $\mathrm{Mcl}-1$ were not affected. This suggests a distinct nexus for PrP action involving Bcl-2 only [112]. In contrast, in a cell-free system PrP was unable to substitute for Bcl-2, and prevent MOMP in the presence of Bax and tBid (a truncated form of the BH3-only protein Bid that triggers MOMP via Bax or Bak) [108]. Pre-incubation of Bax with PrP also had no protective effect. Hence, it appears that PrP does not prevent Bax-mediated apoptosis by direct interaction with Bax. One possibility is that $\alpha \beta$-crystallin which is able to bind Bax [113] may simultaneously bind PrP, which could then mediate indirect interaction between PrP and Bax. This proposed mechanism of simultaneous binding of $\operatorname{PrP}$ and another substrate to $\alpha \beta$-crystallin is an alternative to the mechanism in which $\alpha \beta$-crystallin is sequestered by PrP (as proposed in an earlier section) (Fig. 1). Overall, we suggest that the antiapoptotic activity of PrP acts like the pro-survival Bcl-2 protein (intrinsic pathway) in a Baxdependent manner.

Interactions with key molecules of the intrinsic pathway still do not explain PrP-mediated resistance to pro-apoptotic signals of the extrinsic (TNF, TRAIL) pathway [112]. A possible explanation is that the type of apoptotic signaling repressed by PrP could play an essential role in both the intrinsic and extrinsic apoptotic pathways. There are two types of extrinsic apoptotic signaling (type I and 
type II) that have been defined by differing levels of DISC and caspase-8 activation upon death receptor stimulation. High levels of DISC activation are sufficient to activate initiator and effector caspases triggering apoptosis (type I), while low levels of DISC activation require further amplification of the death signal for apoptosis (type II). Amplification occurs via the BH3-only family protein Bid (or to be precise, its activated form tBid), which engages the intrinsic pathway via Bax or Bak to amplify caspase activity [114]. Hence, the extrinsic pathway can either act independently of the intrinsic pathway or its signals can be amplified through tBid-mediated engagement of the intrinsic pathway. PrP is able to inhibit Bax-mediated apoptosis quite specifically by preventing the conformational change required to activate Bax, but is unable to inhibit Bak or tBid-mediated apoptosis [108]. So PrP would be predicted to inhibit TNF-mediated type II apoptosis via Bax inhibition; however, not type I. Therefore, to explain PrP-mediated resistance to type I apoptosis, we can speculate that PrP also inhibits DISC formation. However, there is evidence that the increased sensitivity of TRAIL-resistant breast carcinoma cell lines to TRAIL following the knockdown/silencing of PrP is not associated with enhanced DISC formation, but instead is associated with caspase processing [112]. Therefore, inhibition of caspase activation is a potential mechanism by which PrP may inhibit TNF-induced type I apoptosis (Fig. 1). However, this warrants further investigation as there are contradictory reports of the effect of $\operatorname{PrP}$ on caspases [99,112,115-118]. Although, the picture may be more complex as another study found that $\alpha \beta$-crystallin can bind caspase-3 and inhibit its autoactivation $[113,119]$. Caspase-3 is an effector caspase that is activated downstream of caspase-8 (extrinsic type I and II pathways) and caspase-9 (intrinsic pathway) to trigger programmed cell death (Fig. 1). This provides a potential mechanism for bringing PrP into contact with caspases and allowing it to influence their activation.

\section{A Possible Role for Prions in Metastasis}

There is evidence that the metastatic potential of some cancers is a phenotype that is subject to cytoplasmic inheritance. This mechanism is observed via exosome transfer. Exosomes are small membrane-enclosed vesicles that contain cytoplasm. Following purification from the culture medium of highly metastatic cancer cells, exosomes conferred increased metastatic activity when fed to poorly metastatic cancer cells [120]. Exosomes are already known to transmit infectious prions between human cells [121]. Therefore, prions may be able to increase the metastatic potential of a tumor mass by exosome transfer from highly aggressive cancer cells. Changes in phenotype within tumor masses resulting in heterogeneity have also been observed when the tumor began as a clonal population. This has been observed in metastasizing cancer cells in animal models of lung cancer [122-123] and sarcoma [124]. The heterogeneity cannot be explained by mutation alone. To date, the molecular mechanisms that cause this phenomenon remain to be elucidated. Generally this 
type of phenotypic alteration has simply been attributed to unusual epigenetic events. However, there are intriguing similarities to the frequent phenotypic alterations in yeast, which are now known to be caused by prions. The phenotypic shift in metastatic cancer cells occurs in a spontaneous, rapid, and reversible manner, resembling those observed in yeast during spontaneous prion induction and curing. Furthermore, the phenotypic alteration and reversion in the metastatic cancer cells were found to occur at the rate of $\sim 1 \times 10^{-5}$ per cell per generation [122]. This is close to the reported frequency of phenotypic alteration due to de novo prion formation and curing in yeast: $1 \times 10^{-5}$ per cell per generation in some studies [102] and in the range of $1 \times 10^{-6}$ per cell per generation in others [125-126]. The frequency of de novo prion induction varies depending on the presence or absence of other prions, e.g. $\left[\mathrm{PIN}^{+}\right]$in the case of $\left[\mathrm{PSI}^{+}\right]$. However, this is generally somewhat higher than the rate of spontaneous mutation (i.e. forward $1 \times 10^{-6}$ and back $1 \times 10^{-8}$ per cell per generation) [101]. In fact, phenotypic heterogeneity of tumor cell subpopulations has long been observed despite the cells being derived from the same primary tumor and, therefore, originally possessing identical genomes [127]. Phenotypic heterogeneity within a genetically identical population of cells is a hallmark of protein-only inheritance mediated by prions in yeast and other fungi. Prions provide a mechanism that can create variant subpopulations with distinct phenotypes within isogenic populations $[22,128]$. Whether analogous molecular mechanisms to those that are now known to underlie spontaneous prion induction and prion-mediated phenotypic alteration in yeast and other fungi also play a role in the generation of phenotypic heterogeneity (e.g. drug resistance, metastatic potential, altered expression of tumor cell markers, development of genomic instability) in cancer in humans clearly warrants investigation.

Prion induction in mammals may also play a role in cancer metastasis. The role of PrP in the regulation of signaling pathways is known to be important for cancer metastasis. Over-expression of PrP (which could induce prionization, but this has not yet been tested in cancer) significantly promotes the adhesive, invasive, and in vivo metastatic phenotype of gastric cancer cell lines via inducing phosphorylation of phosphatidylinositol 3-kinase/Akt (PI3K/Akt) and activation of the Akt pathway (Figure 1) [129]. Moreover, activated Akt is known to phosphorylate the MAP kinase ERK1/2 thereby promoting increased expression of matrix metalloproteinase 11 (MMP11) in gastric and pancreatic cancer cells (Fig. 1) [106,129-130]. Metalloproteinases are responsible for extracellular matrix (ECM) degradation, which is an essential step in tumor invasion and metastasis. It was also shown that inhibition of the MEK/ERK MAP kinase signaling pathway reduced $\operatorname{PrP}$ over-expression and inhibited gastric cancer metastasis [130,106]. Furthermore, PrP expression levels have been shown to negatively influence pancreatic cancer patient survival due to $\operatorname{PrP}$ interaction with filamin a (FLNa), an actin-associated protein that integrates cell mechanics and 
signaling. PrP contains a filamin A-binding (FLNa-binding) motif, which interacts with FLNa in pancreatic cancer cell lines [14]. Binding of FLNa alters the organization of the cytoskeleton and expression of multiple signaling proteins. PrP overexpression and binding to FLNa result in increased cellular proliferation and invasiveness in vitro, as well as tumor growth in vivo. This also inversely correlated with patient wellbeing [14]. Taken together these observations suggest that $\operatorname{PrP}$ plays a role in metastasis by activating various stress-activated kinase signaling pathways.

In addition to members of the kinase signaling pathways, important cell cycle regulatory proteins like the key tumor suppressor p53 can influence metastasis via changes in its protein structure. Inactivation of p53 function has been linked to the progression of cancer and is observed in greater than $50 \%$ of all human cancers [131]. The resulting loss of p53 activity is implicated to affect expression of more than 1,500 genes, the majority of which are involved in key metabolic processes including DNA damage response, cell cycle regulation or activation of apoptosis [132-133]. Interestingly, the individual domains of p53 are able to form amyloid-like aggregates, including the core, the tetramerization and the transactivation domains [134-137]. Further, it has been demonstrated that the p53 N-terminal domain aggregates into amyloid assemblies that exhibit cytotoxicity [137]. Mutant p53 is also able to drive conversion of the wild type p53 protein into a non-functional conformation in a way that resembles the actions of amyloid prions [138], thereby disrupting normal p53 physical interactions with its partner proteins and p53 trans-activation function. The mutant p53 amyloid form can confer a dominant phenotype on the remaining wildtype p53 form of protein and sequester native p53 in an inactive conformation [77]. This would result in altered signaling, inhibition of apoptosis, promotion of cell cycle progression, and increased metastatic potential. However, another study has found that mesenchymal embryonic cells transformed by Ras/Myc and engineered for knockout of the PRNP gene displayed an increased incidence of lung metastasis due to increased expression of $\alpha_{\mathrm{V}} \beta_{3}$-integrin and blood aggregates [139]. The knockout of $P R N P$ may phenocopy the infection of $\operatorname{PrP}^{\mathrm{C}}$ by a prion $\left(\operatorname{PrP}^{\mathrm{Sc}}\right)$, which would result in reduced function of $\operatorname{PrP}^{\mathrm{C}}$. These results suggest that $\operatorname{Pr} \mathrm{P}$ negatively modulates the expression and activation of integrin $\alpha_{V} \beta_{3}$ thus repressing a more aggressive cancer phenotype. The capability of prions to 'infect' neighboring cells and disrupt cellular processes is a potential mechanism for promoting cancer progression. Overall, it is an intriguing possibility, although yet to be tested, that infection of $\operatorname{PrP}^{\mathrm{C}}$ with a prion and its functional inactivation may be responsible for cancer phenotypes.

\section{Implications for prevention, early diagnosis, and targeted therapeutic intervention in cancer}




\section{Implications for Future Cancer Prevention}

New environmental factors that trigger altered protein conformation (but not DNA damage) might represent a whole new class of carcinogens. These potential new discoveries could aid in improved screening for environmental factors and cancer prevention.

\section{Implications for Future Early Diagnosis of Cancer}

It is notable that the incubation period for well-characterized prion-mediated diseases (e.g. $\operatorname{PrP}^{\mathrm{Sc}}$ ) is variable, but can be as long as 50-60 years [140]. So there could potentially be a significant time between diagnosis and the appearance of disease in which to intervene therapeutically if there were a prion involvement in cancer. If prion proteins contribute to cancer and altered protein conformation is a trigger for cancer initiation, then molecular diagnostics tools could be designed specifically to recognize the altered prion form of the protein, i.e. conformation-specific antibodies. This would facilitate early diagnosis of cancer and potentially provide population-wide screens. Considering this potential and the various prion-mediated mechanisms, we discuss below some prospective targets for intervention.

\section{Implications for Future Targeted Intervention in Cancer}

Prions have the potential to contributor to the initiation of cancer by creating altered patterns of global gene expression and by inhibition of normal homeostatic mechanisms promoting the accumulation of oncogenic mutations and altered ploidy often observed in cancer. However, prions also have the potential to act in later stages of oncogenesis by generating the phenotypic heterogeneity required for metastasis, angiogenesis, and drug resistance. Thus targeting prions may be an excellent complementary therapy that could realistically enhance conventional anti-cancer therapies. While targeting of prions per se has not yet been tested therapeutically in cancer, several studies have explored whether the human protein known to be susceptible to prion infection and to exhibit upregulated expression in cancer, PrP, is a potential anti-cancer target. PrP-mediated changes in signaling can potentially contribute to cancer progression in several ways: (1) $\operatorname{PrP}$

(whether $\operatorname{PrP}^{\mathrm{C}}$ or $\operatorname{Prp}^{\mathrm{Sc}}$ was not tested) exhibits physical interaction with chaperones via its unstructured domain that attracts HSPs and chaperones, (2) it shifts the balance of apoptotic signals towards survival and (3) it affects pro-metastatic signaling pathways. The direct targeting of $\operatorname{PrP}$ with anti-PrP antibodies has been demonstrated as a potential cancer therapy via induction of apoptosis [141]. However, the most efficient therapeutic responses were seen when anti-PrP antibodies were used in combination with other therapies. Antibodies to PrP enhanced the effect of anti-tumor drugs irinotecan, 5-fluorouracil, cisplatin and doxorubicin to varying degrees [141]. Critical analysis of PrP molecular interactions shows that PrP is able to activate the PI3K/Akt 
pathway and thus contribute to cell survival (Figure 1). Activated PI3K/Akt is known to significantly contribute to resistance to chemotherapy and thus suppression of the PI3K-Akt axis can sensitize cells in combination therapies [142]. The dual mechanisms of sensitizing cells with PI3K/Akt inhibition in conjunction with targeting the anti-apoptotic function of $\operatorname{PrP}$ may be effective in cancers with PrP over-expression including gastric, breast, colon, pancreatic, and prostate cancers $[12,14,16,112,141]$. For example, treatment with the PI3K inhibitors wortmannin and LY294002 resulted in decreased levels of phosphorylated Akt [143]. PI3K/Akt inhibition was sufficient to sensitize cancer cells to apoptosis induced by a second agent in pancreatic cancer cell lines [144], salivary gland cancers [145], breast cancer cell lines [146], colon cancer cells [147] and metastatic prostate cancer cells [148], all of which express high levels of PrP. Prion-targeted therapies may provide effective treatment wherever prions confer an infectious phenotype that contributes to disease progression.

\section{Targeting Phenotypic Reversion or Curing of Prions in Cancer}

An alternative approach for intervention could be to identify and "cure" amyloid prions. Yeast prions can be stably maintained in animal cell lines [149] and chemical treatments that cure yeast of prions can also cure animal cell lines of the $\mathrm{PrP}^{\mathrm{Sc}}$ prion [150]. Therefore, we suggest that translational research for discovery of potential therapies for the treatment of prion-mediated disease (possibly including cancer) may be developed from the well characterized yeast models and adapted for mammalian disease. In yeast, a transient exposure to cell-permeable protein denaturing agents, in particular guanidinium chloride $(\mathrm{GuHCl})$, has a strong influence on prion reversion. Denaturation strongly enhances phenotypic reversion of yeast prions (also called “curing”) [151]. Pharmaceutical reversion of the amyloid prion could help induce cell death. Recent studies have identified tricyclic derivatives of acridine and phenothiazine as chemical inhibitors of amyloid prion induction and maintenance [152]. Of these, the most effective anti-prion chemicals were found to be quinacrine (anti-malarial) and chlorpromazine (anti-depressant). Each of these compounds has been shown to be effective against both yeast and mammalian prions ( $\mathrm{PrP}^{\mathrm{Sc}}$ ) [150]. Since these compounds represent drugs that are already in current clinical use and are known to cross the bloodbrain barrier, they could be immediate candidates for the treatment of amyloid prion-mediated diseases including, potentially, various cancers.

On a related note, given the role of prions in modulating protein folding, it is intriguing to find reports of controversial cancer therapies like hyperthermia treatment which involve placing a patient in an incubator at high temperature (up to $45^{\circ} \mathrm{C}$ ) for a period of time [153]. Heat sensitivity in vitro is often cited as evidence for the involvement of proteins in a biochemical process and it is 
also known that in vivo, heat affects protein folding. At a molecular level, hyperthermia shifts the thermodynamic equilibrium and hence, would be expected to destabilize normal protein structure and conformations, which in turn would affect protein function. At higher temperatures, proteins could form different conformations in order to stabilize. Hence, if prions contribute to cancer, hyperthermia treatment could cure cancer by curing (yet to be identified) prions. This could possibly account for the apparent tumor cell selectivity of hyperthermia treatment and provide a hypothesis for the molecular basis of hyperthermia therapy.

\section{Targeting Drug Resistance and Metastasis in Cancer}

Drug resistance and metastasis are both known to be influenced by $\operatorname{PrP}$ (whether $\operatorname{PrP}^{\mathrm{C}}$ or $\operatorname{Prp}^{\mathrm{Sc}}$ was not tested) and can be targeted in different ways. The molecular mechanism of multi-drug resistance (MDR) in cancer cells has long been associated with P-glycoprotein, an energy-dependent multidrug efflux pump (reviewed in [154]). Recently, it was shown that PrP interacts with P-glycoprotein and is essential for drug resistance in breast cancer cells [155]. Several studies have also functionally linked MDR and tumor metastasis [156-159]. In fact, depletion of PrP inhibited MDRinduced metastasis of breast cancer cells [155]. Interestingly, emerging evidence also suggests that different prion strains can confer drug resistance in cell populations via natural selection and conformational fitness [160]. As mentioned above, another mechanism by which PrP promotes metastasis is the activation of the Akt pathway (Fig. 1). Inhibition of Akt kinase activity or knockdown of Akt with siRNA has been shown to inhibit PrP-associated drug resistance in gastric cancer cells [130]. Furthermore, the anti-prion drug chlorpromazine, that is effective against mammalian prions, has been shown to prevent the development of resistance to ionizing radiation and anti-tumor drugs in cancer cells [161-162].

\section{Conclusion}

The activity of prion proteins to induce protein-only inheritance in the context of formation and progression of cancer has extensive circumstantial evidence (summarized in Table 3). Prion protein over-expression and influences on apoptosis, kinase signaling, and sequestration of chaperones implies that conversion of a normal cellular protein to a prion and the ensuing metabolic disruption can potentially enhance the cancer phenotypes. That prions such as $\mathrm{PrP}^{\mathrm{Sc}}$ are infectious (transferred via exosomes) suggests the possibility that prion induction may also promote the transfer of the cancer phenotype to neighboring cells. This could potentially promote the rapid development of phenotypic heterogeneity, including resistance to chemotherapeutics, cancer invasion and metastasis, preceding the appearance of genetic mutations. Thus, there is a need to define the role in 
cancer of $\operatorname{PrP}^{\mathrm{C}}$ itself, prions that infect $\operatorname{PrP}^{\mathrm{C}}$ (like $\operatorname{Prp}^{\mathrm{Sc}}$ ) and potentially other yet to be discovered prions that may affect other cellular signaling proteins contributing to cancer. The knowledge obtained could be utilized to develop potential strategies for more effective prevention, early diagnosis, prognostic assessment, and therapeutic intervention in prion-dependent diseases, which may well include various types of cancer.

\section{Acknowledgements}

The authors gratefully acknowledge research grant funding from the Australian Research Council (ARC DP110100389) to ALM, MQW \& YOC; the National Health and Medical Research Council

(Program Grant ID: 442903) to KK; a Dr. Jian Zhou Smart State Fellowship (Queensland State Government), the NH\&MRC, and Cancer Council Queensland to MQW; and the National Institutes of Health (R01GM58763) to YOC. 
Figure 1. A schematic diagram showing the molecular interactions of the cellular prion protein (PrP). The cellular prion protein (PrP) consists of $3 \alpha$-helical domains and a highly disordered but functionally conserved N-terminal domain that interacts with a number of key regulatory proteins of several pathways to promote cell survival and proliferation. PrP has been shown to directly bind the chaperone protein $\alpha \beta$-crystallin which could then promote cell cycle progression via de-repression of cyclin D1 and also via the conversion of the p53 tumor suppressor to a mutant conformation. PrP can inhibit the activation of both the extrinsic and intrinsic apoptotic pathways. It can potentially inhibit the activation of caspases and/or pro-apoptotic Bax and promote the stabilization of the pro-survival protein Bcl-2. PrP over-expression can also activate the PI3k/Akt pathway promoting cancer cell invasion and metastasis via increased expression of the matrix metalloproteinase 11 (MMP11). A putative prion infected mutant p53 could promote cell cycle progression and prevent apoptosis via the functional alteration of wild-type p53. Solid arrows in the figure indicate documented interactions from the literature and dashed arrows indicate hypothetical interactions proposed in this review.

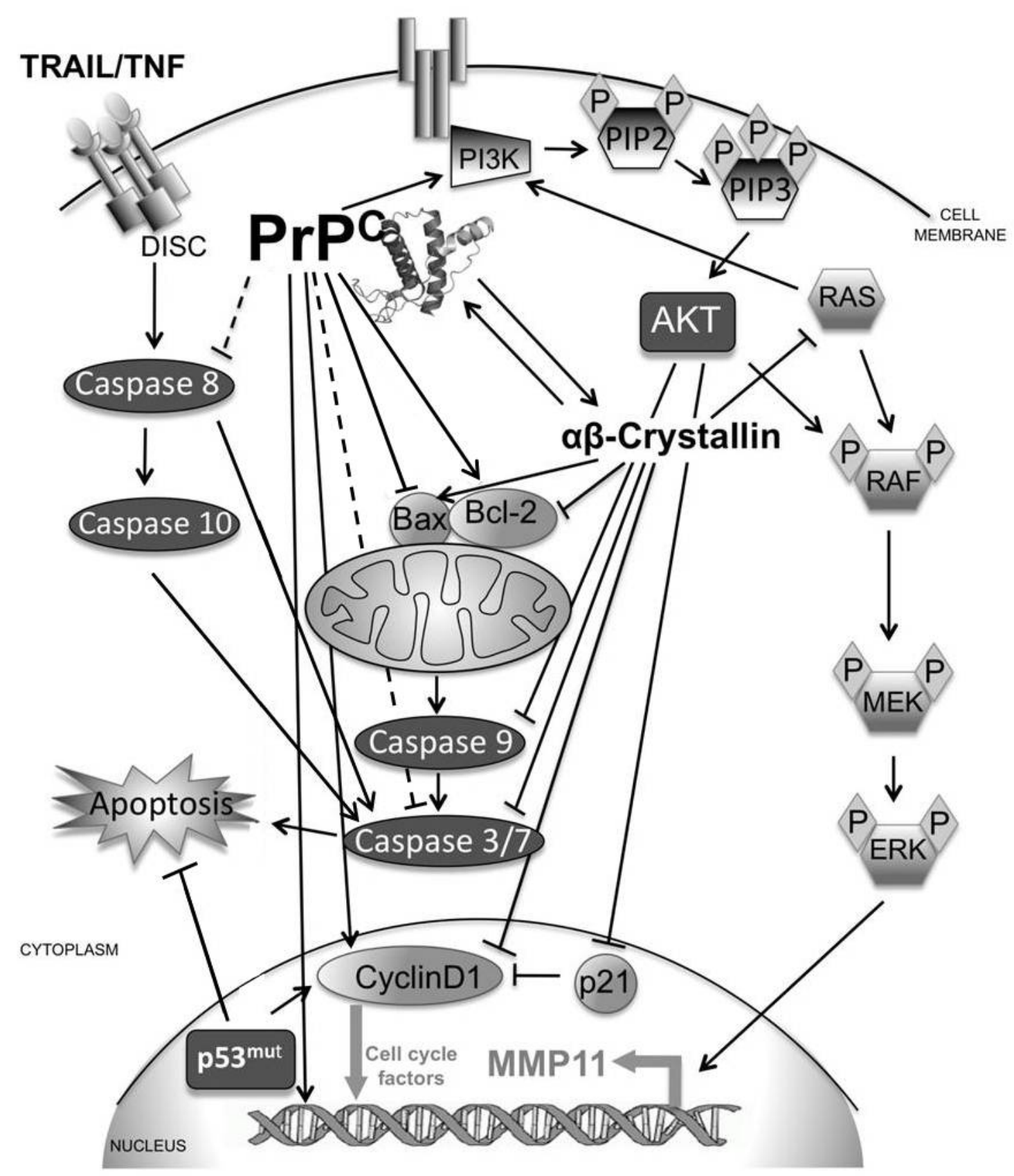




\section{Table 1. Currently known roles of $\operatorname{PrP}$ (whether $\operatorname{PrP}^{\mathrm{C}}$ or $\operatorname{Prp}^{\mathrm{Sc}}$ was not tested) in different types of cancers}

\begin{tabular}{|c|c|c|c|}
\hline $\begin{array}{l}\text { Cancer } \\
\text { type }\end{array}$ & Expression of PrP & $\begin{array}{l}\text { Conformation } \\
\text { of PrP in vivo }\end{array}$ & Functions/Properties of PrP observed \\
\hline Gastric & $\begin{array}{l}\text { Highly expressed in } \\
\text { metastatic cells [129] }\end{array}$ & $\begin{array}{l}\text { Non-prionic form } \\
\text { - } \operatorname{PrP}^{\mathrm{C}}\end{array}$ & $\begin{array}{l}\text { - PrP promoted adhesive, invasive, and in vivo metastatic } \\
\text { abilities through activation of MEK/ERK pathway and } \\
\text { consequent transactivation of MMP11 [129] } \\
\text { PrP slowed down apoptosis via suppression of ROS and } \\
\text { upregulation of Bcl-2 [99] } \\
\text { - Increased PrP expression in gastric adenocarcinomas correlated } \\
\text { with histopathological differentiation and tumor progression } \\
\text { [129] } \\
\text { PrP expression was related to multidrug resistance in gastric } \\
\text { cancer [12] }\end{array}$ \\
\hline Breast & $\begin{array}{l}\text { Expressed in normal } \\
\text { breast tissue mainly by } \\
\text { myoepithelial cells, } \\
\text { but specifically } \\
\text { associated with ER- } \\
\text { negative breast } \\
\text { cancers [11] }\end{array}$ & Not verified & $\begin{array}{l}\text { - PrP expression correlated with metastatic invasiveness [141] } \\
\text { and resistance to chemotherapy, possibly via resistance to cell } \\
\text { death (ie. TNF-induced apoptosis) [100,11] } \\
\text { - Silencing of PrP sensitized breast carcinoma cells to TRAIL- } \\
\text { mediated cell death [112] }\end{array}$ \\
\hline Colorectal & $\begin{array}{l}\text { Highly elevated PrP } \\
\text { expression in } \\
\text { neoplastic compared } \\
\text { to normal tissue [13]. } \\
\text { Over-expression of } \\
\text { PRNP in human } \\
\text { colorectal cancers [17] }\end{array}$ & Not verified & $\begin{array}{l}\text { - PrP levels correlated with metastatic invasiveness in colon } \\
\text { cancer cell lines [141] } \\
\text { - PrP antibody is an effective anticancer therapy that reduced cell } \\
\text { proliferation, with increased efficiency in combination } \\
\text { chemotherapy [141] } \\
\text { - PrP can serve as a cancer marker - data suggested that cells may } \\
\text { be using PrP as a mechanism to aid cell proliferation and } \\
\text { aggressive tumors over-expressed PrP as an anti-apoptotic } \\
\text { mechanism [141] } \\
\text { PrP can serve as a prognostic marker - protein levels correlated } \\
\text { with disease recurrence [13] }\end{array}$ \\
\hline Pancreatic & $\begin{array}{l}\text { PrP is not detected in } \\
\text { normal human } \\
\text { pancreatic } \\
\text { ductal cells but is } \\
\text { expressed in human } \\
\text { PDAC cell lines [14] } \\
\text { and } 40 \% \text { of pancreatic } \\
\text { cancer patients [15]. } \\
\text { PRNP is over- } \\
\text { expressed in } \\
\text { pancreatic cancer cell } \\
\text { lines [18] }\end{array}$ & $\begin{array}{l}\text { In PDAC, PrP } \\
\text { existed as a pro- } \\
\text { PrP which was } \\
\text { neither } \\
\text { glycosylated nor } \\
\text { GPI anchored, but } \\
\text { retained its GPI } \\
\text { anchor } \\
\text { peptide signal } \\
\text { sequence [14] }\end{array}$ & $\begin{array}{l}\text { - } \quad \text { pro-PrP binds to FLNa, which disrupts the normal functions of } \\
\text { FLNa and confers a growth advantage to PDAC [14] } \\
\text { - Downregulation of PrP altered the organization of actin } \\
\text { filaments and signaling events in PDAC cell lines [14] } \\
\text { - PrP modulated the proliferation, invasiveness, and growth of } \\
\text { - PDAC cell lines [14] } \\
\text { PrP expression in tumors correlated with a marked decrease in } \\
\text { patient survival [14] }\end{array}$ \\
\hline Prostrate & $\begin{array}{l}\text { PrP is expressed in } \\
\text { multi-cellular prostate } \\
\text { tumor spheroids } \\
\text { of the androgen- } \\
\text { independent Du-145 } \\
\text { cancer cell } \\
\text { lines [16] }\end{array}$ & Not verified & $\begin{array}{l}\text { PrP expression correlated with the intracellular redox state of } \\
\text { tumor spheroids, which suggests a role for PrP in the anti- } \\
\text { oxidative defense system [16] }\end{array}$ \\
\hline
\end{tabular}


Table 2. Comparison of yeast and mammalian prion characteristics

\begin{tabular}{|l|l|l|}
\hline Characteristics of Prions & \multicolumn{2}{c}{ Yeast Prions } \\
\hline Conformational diversity & $\begin{array}{l}\text { Prion “variants” with diverse } \\
\text { conformations demonstrate } \\
\text { differences in phenotypic } \\
\text { manifestation and stability of } \\
\text { maintenance [26-27,33,39] }\end{array}$ & $\begin{array}{l}\text { Prion “strains” with diverse } \\
\text { conformations and/or } \\
\text { glycosylation patterns exhibit } \\
\text { specific incubation times, } \\
\text { different distribution of } \\
\text { vacuolar brain lesions, varied } \\
\text { accumulation patterns or } \\
\text { different activity states [4,62] }\end{array}$ \\
\hline Formation of amyloid fibrils/aggregates & Yes [6-7,21,23] & Yes [4,19] \\
\hline Resistance to proteinase K & Resistant [6,8] & Resistant [19] \\
\hline Intercellular aggregate propagation in vivo & Unknown & Via exosomes [121] \\
\hline Prion forming domains (PrDs) & $\begin{array}{l}\text { Yes } \rightarrow \text { Q/N-rich PrDs } \\
\text { present in the N-terminus [7- } \\
\text { 8], except in [Het-s] which } \\
\text { has a non Q/N rich PrD in its } \\
\text { C-terminus [79] }\end{array}$ & $\begin{array}{l}\text { Yes } \rightarrow \text { Q/N rich or non Q/N } \\
\text { rich PrDs present in the N- } \\
\text { terminus [59-60,66-67] }\end{array}$ \\
\hline $\begin{array}{l}\text { Interaction with and dependency on chaperones } \\
\text { denaturation) }\end{array}$ & $\begin{array}{l}\text { Yes e.g. Hsp104p [8,54,83], } \\
\text { Hsp70p [8], Sis1p (Hsp40) } \\
\text { [8], etc. }\end{array}$ & $\begin{array}{l}\text { Yes e.g. } \alpha \beta \text {-crystallin (sHsp) } \\
\text { [84] }\end{array}$ \\
\hline & $\begin{array}{l}\text { Yes } \rightarrow \text { Treatment with } \\
\text { GuHCl or ablation of } \\
\text { Hsp104p function [151] }\end{array}$ & $\begin{array}{l}\text { Yes } \rightarrow \text { Treatment with } \\
\text { Guanidine [163] or GuHCl } \\
\text { [164] }\end{array}$ \\
\hline
\end{tabular}


Table 3. Summary of similarities between mechanisms observed in prions and cancer

Mechanisms in Prions

\begin{tabular}{|l|l|}
\hline Have a long incubation period [140] & $\begin{array}{l}\text { Sporadic cancers are often late-onset (i.e. } \\
\text { increased incidence with age) [165-166] }\end{array}$ \\
\hline $\begin{array}{l}\text { Frequency of reversible phenotypic switching } \\
\text { observed in prions: } 10^{-5}-10^{-7} \text { per cell per } \\
\text { generation [52,102] }\end{array}$ & $\begin{array}{l}\text { Frequency of phenotypic alteration and } \\
\text { reversion observed in metastatic cancer cells: } \\
\sim 10^{-5} \text { per cell per generation [122] }\end{array}$ \\
\hline Heritably increase phenotypic diversity [128] & $\begin{array}{l}\text { Heritable phenotypic heterogeneity in tumor cell } \\
\text { subpopulations derived from the same primary } \\
\text { cell [127,122,124,123] }\end{array}$ \\
\hline $\begin{array}{l}\text { Exosomes transmit infectious prions between } \\
\text { human cells [121] }\end{array}$ & $\begin{array}{l}\text { Exosomes confer metastatic activity to cells } \\
\text { [120] }\end{array}$ \\
\hline $\begin{array}{l}\text { Chlorpromazine is an effective drug against both } \\
\text { yeast and mammalian prions [150] }\end{array}$ & $\begin{array}{l}\text { Chlorpromazine prevents the development of } \\
\text { resistance to ionizing radiations and anti-tumor } \\
\text { drugs in cancer cells [161-162] }\end{array}$ \\
\hline $\begin{array}{l}\text { Prion form of MAPKKK causes self- } \\
\text { hyperactivation of MAPKKK such that it } \\
\text { becomes independent of upstream signals [49] }\end{array}$ & $\begin{array}{l}\text { Auto-activation of MAPK signaling is one of the } \\
\text { molecular mechanisms of cancer [50] }\end{array}$ \\
\hline $\begin{array}{l}\text { Over-expression of PrP observed in prion } \\
\text { diseases [3-5] }\end{array}$ & $\begin{array}{l}\text { Highly elevated PrP expression in many cancers } \\
\text { (Table 1) }\end{array}$ \\
\hline $\begin{array}{l}\text { May increase phenotypic plasticity and therefore } \\
\text { the ability of yeast to survive adverse } \\
\text { environmental conditions [29] }\end{array}$ & $\begin{array}{l}\text { Drug resistance [11,130], metastasis [14,129] } \\
\text { and anti-apoptotic mechanisms [100,112] } \\
\text { observed and can be influenced by PrP }\end{array}$ \\
\hline $\begin{array}{l}\text { Different prion strains confer drug resistance in } \\
\text { cell populations via natural selection and } \\
\text { conformational fitness [160] }\end{array}$ & $\begin{array}{l}\text { Depletion of PrP inhibits multi-drug resistance- } \\
\text { induced metastasis of breast cancer cells [155] }\end{array}$ \\
\hline
\end{tabular}




\section{References}

1. Balmain, A., Gray, J., \& Ponder, B. (2003). The genetics and genomics of cancer. Nature Genetics, 33 Suppl, 238-244.

2. Hunt, K. S., \& Ray, J. A. (2008). Hereditary Risk for Cancer. In D. S. Alberts, \& L. M. Hess (Eds.), Fundamentals of Cancer Prevention (pp. 109-135). Berlin Heidelberg: Springer.

3. Prusiner, S. B. (1982). Novel proteinaceous infectious particles cause scrapie. Science, 216(4542), 136-144.

4. Prusiner, S. B. (1998). Prions. Proceedings of the National Academy of Sciences of the United States of America, 95(23), 13363-13383.

5. Dormont, D. (2002). Prion diseases: pathogenesis and public health concerns. FEBS Letters, 529(1), 17-21.

6. Wickner, R. B., Edskes, H. K., Shewmaker, F., Nakayashiki, T., Engel, A., McCann, L., et al. (2007). Yeast prions: evolution of the prion concept. Prion, 1(2), 94-100, doi:4664 [pii].

7. Inge-Vechtomov, S. G., Zhouravleva, G. A., \& Chernoff, Y. O. (2007). Biological roles of prion domains. Prion, 1(4), 228-235.

8. Shkundina, I. S., \& Ter-Avanesyan, M. D. (2007). Prions. Biochemistry, 72(13), 1519-1536.

9. Mehrpour, M., \& Codogno, P. (2010). Prion protein: From physiology to cancer biology. Cancer Letters, 290(1), 1-23.

10. Hanahan, D., \& Weinberg, R. A. (2011). Hallmarks of cancer: the next generation. Cell, 144(5), 646-674.

11. Meslin, F., Conforti, R., Mazouni, C., Morel, N., Tomasic, G., Drusch, F., et al. (2007). Efficacy of adjuvant chemotherapy according to Prion protein expression in patients with estrogen receptor-negative breast cancer. Annals of Oncology, 18(11), 1793-1798.

12. Du, J., Pan, Y., Shi, Y., Guo, C., Jin, X., Sun, L., et al. (2005). Overexpression and significance of prion protein in gastric cancer and multidrug-resistant gastric carcinoma cell line SGC7901/ADR. International Journal of Cancer, 113(2), 213-220.

13. Antonacopoulou, A. G., Palli, M., Marousi, S., Dimitrakopoulos, F. I., Kyriakopoulou, U., Tsamandas, A. C., et al. (2010). Prion protein expression and the M129V polymorphism of the PRNP gene in patients with colorectal cancer. Molecular Carcinogenesis, 49(7), 693699.

14. Li, C., Yu, S., Nakamura, F., Yin, S., Xu, J., Petrolla, A. A., et al. (2009). Binding of pro-prion to filamin A disrupts cytoskeleton and correlates with poor prognosis in pancreatic cancer. Journal of Clinical Investigation, 119(9), 2725-2736.

15. Sy, M. S., Li, C., Yu, S., \& Xin, W. (2010). The fatal attraction between pro-prion and filamin A: prion as a marker in human cancers. Biomarkers in Medicine, 4(3), 453-464.

16. Sauer, H., Dagdanova, A., Hescheler, J., \& Wartenberg, M. (1999). Redox-regulation of intrinsic prion expression in multicellular prostate tumor spheroids. Free Radical Biology and Medicine, 27(11-12), 1276-1283.

17. Antonacopoulou, A. G., Grivas, P. D., Skarlas, L., Kalofonos, M., Scopa, C. D., \& Kalofonos, H. P. (2008). POLR2F, ATP6V0A1 and PRNP expression in colorectal cancer: new molecules with prognostic significance? Anticancer Research, 28(2B), 1221-1227.

18. Han, H., Bearss, D. J., Browne, L. W., Calaluce, R., Nagle, R. B., \& Von Hoff, D. D. (2002). Identification of differentially expressed genes in pancreatic cancer cells using cDNA microarray. Cancer Research, 62(10), 2890-2896.

19. Giles, K., Glidden, D. V., Beckwith, R., Seoanes, R., Peretz, D., DeArmond, S. J., et al. (2008). Resistance of bovine spongiform encephalopathy (BSE) prions to inactivation. PLoS Pathogens, 4(11), e1000206.

20. Supattapone, S., Bouzamondo, E., Ball, H. L., Wille, H., Nguyen, H. O., Cohen, F. E., et al. (2001). A protease-resistant 61-residue prion peptide causes neurodegeneration in transgenic mice. Molecular and Cellular Biology, 21(7), 2608-2616. 
21. Alberti, S., Halfmann, R., King, O., Kapila, A., \& Lindquist, S. (2009). A systematic survey identifies prions and illuminates sequence features of prionogenic proteins. Cell, 137(1), 146-158.

22. Halfmann, R., \& Lindquist, S. (2010). Epigenetics in the Extreme: Prions and the Inheritance of Environmentally Acquired Traits. Science, 330(6004), 629-632.

23. Li, L., \& Lindquist, S. (2000). Creating a protein-based element of inheritance. Science, 287(5453), 661-664.

24. Brachmann, A., Baxa, U., \& Wickner, R. B. (2005). Prion generation in vitro: amyloid of Ure2p is infectious. EMBO Journal, 24(17), 3082-3092.

25. Patel, B. K., \& Liebman, S. W. (2007). "Prion-proof" for [PIN+]: infection with in vitro-made amyloid aggregates of Rnq1p-(132-405) induces [PIN+]. Journal of Molecular Biology, 365(3), 773-782.

26. Tanaka, M., Chien, P., Naber, N., Cooke, R., \& Weissman, J. S. (2004). Conformational variations in an infectious protein determine prion strain differences. Nature, 428(6980), 323-328.

27. Derkatch, I. L., Chernoff, Y. O., Kushnirov, V. V., Inge-Vechtomov, S. G., \& Liebman, S. W. (1996). Genesis and variability of [PSI] prion factors in Saccharomyces cerevisiae. Genetics, 144(4), 1375-1386.

28. Cox, B. S. (1965). [Psi], A cytoplasmic suppressor of super-suppressor in yeast. Heredity, 20(4), 505-521.

29. True, H. L., \& Lindquist, S. L. (2000). A yeast prion provides a mechanism for genetic variation and phenotypic diversity. Nature, 407(6803), 477-483.

30. Chernoff, Y. O., Galkin, A. P., Lewitin, E., Chernova, T. A., Newnam, G. P., \& Belenkiy, S. M. (2000). Evolutionary conservation of prion-forming abilities of the yeast Sup35 protein. Molecular Microbiology, 35(4), 865-876.

31. Nakayashiki, T., Kurtzman, C. P., Edskes, H. K., \& Wickner, R. B. (2005). Yeast prions [URE3] and [PSI+] are diseases. Proceedings of the National Academy of Sciences of the United States of America, 102(30), 10575-10580.

32. Resende, C. G., Outeiro, T. F., Sands, L., Lindquist, S., \& Tuite, M. F. (2003). Prion protein gene polymorphisms in Saccharomyces cerevisiae. Molecular Microbiology, 49(4), 10051017.

33. McGlinchey, R. P., Kryndushkin, D., \& Wickner, R. B. (2011). Suicidal [PSI+] is a lethal yeast prion. Proceedings of the National Academy of Sciences of the United States of America, 108(13), 5337-5341.

34. Lacroute, F. (1971). Non-Mendelian mutation allowing ureidosuccinic acid uptake in yeast. Journal of Bacteriology, 106(2), 519-522.

35. Wickner, R. B. (1994). [URE3] as an altered URE2 protein: evidence for a prion analog in Saccharomyces cerevisiae. Science, 264(5158), 566-569.

36. Brown, J. C., \& Lindquist, S. (2009). A heritable switch in carbon source utilization driven by an unusual yeast prion. Genes and Development, 23(19), 2320-2332.

37. Derkatch, I. L., Bradley, M. E., Zhou, P., Chernoff, Y. O., \& Liebman, S. W. (1997). Genetic and environmental factors affecting the de novo appearance of the [PSI+] prion in Saccharomyces cerevisiae. Genetics, 147(2), 507-519.

38. Derkatch, I. L., Bradley, M. E., Hong, J. Y., \& Liebman, S. W. (2001). Prions affect the appearance of other prions: the story of [PIN(+)]. Cell, 106(2), 171-182.

39. Bagriantsev, S., \& Liebman, S. W. (2004). Specificity of prion assembly in vivo. [PSI+] and [PIN+] form separate structures in yeast. Journal of Biological Chemistry, 279(49), 5104251048.

40. Du, Z., Park, K. W., Yu, H., Fan, Q., \& Li, L. (2008). Newly identified prion linked to the chromatin-remodeling factor Swi1 in Saccharomyces cerevisiae. Nature Genetics, 40(4), 460-465. 
41. Patel, B. K., Gavin-Smyth, J., \& Liebman, S. W. (2009). The yeast global transcriptional corepressor protein Cyc8 can propagate as a prion. Nature Cell Biology, 11(3), 344-349.

42. Rogoza, T., Goginashvili, A., Rodionova, S., Ivanov, M., Viktorovskaya, O., Rubel, A., et al. (2010). Non-Mendelian determinant [ISP+] in yeast is a nuclear-residing prion form of the global transcriptional regulator Sfp1. Proceedings of the National Academy of Sciences of the United States of America, 107(23), 10573-10577.

43. Tuite, M. F., \& Cox, B. S. (2009). Prions remodel gene expression in yeast. Nature Cell Biology, 11(3), 241-243.

44. Coustou, V., Deleu, C., Saupe, S., \& Begueret, J. (1997). The protein product of the het-s heterokaryon incompatibility gene of the fungus Podospora anserina behaves as a prion analog. Proceedings of the National Academy of Sciences of the United States of America, 94(18), 9773-9778.

45. Ritter, C., Maddelein, M. L., Siemer, A. B., Luhrs, T., Ernst, M., Meier, B. H., et al. (2005). Correlation of structural elements and infectivity of the HET-s prion. Nature, 435(7043), 844-848.

46. Loubradou, G., \& Turcq, B. (2000). Vegetative incompatibility in filamentous fungi: a roundabout way of understanding the phenomenon. Research in Microbiology, 151(4), 239245.

47. Maddelein, M. L., Dos Reis, S., Duvezin-Caubet, S., Coulary-Salin, B., \& Saupe, S. J. (2002). Amyloid aggregates of the HET-s prion protein are infectious. Proceedings of the National Academy of Sciences of the United States of America, 99(11), 7402-7407.

48. Roberts, B. T., \& Wickner, R. B. (2003). Heritable activity: a prion that propagates by covalent autoactivation. Genes and Development, 17(17), 2083-2087.

49. Kicka, S., Bonnet, C., Sobering, A. K., Ganesan, L. P., \& Silar, P. (2006). A mitotically inheritable unit containing a MAP kinase module. Proceedings of the National Academy of Sciences of the United States of America, 103(36), 13445-13450.

50. Brinkman, J. A., \& El-Ashry, D. (2009). ER re-expression and re-sensitization to endocrine therapies in ER-negative breast cancers. Journal of Mammary Gland Biology and Neoplasia, 14(1), 67-78.

51. Derkatch, I. L., Bradley, M. E., Masse, S. V., Zadorsky, S. P., Polozkov, G. V., IngeVechtomov, S. G., et al. (2000). Dependence and independence of [PSI(+)] and [PIN(+)]: a two-prion system in yeast? EMBO Journal, 19(9), 1942-1952.

52. Tyedmers, J., Madariaga, M. L., \& Lindquist, S. (2008). Prion switching in response to environmental stress. PLoS Biology, 6(11), e294.

53. Chernoff, Y. O. (2007). Stress and prions: lessons from the yeast model. FEBS Letters, 581(19), 3695-3701.

54. Romanova, N. V., \& Chernoff, Y. O. (2009). Hsp104 and prion propagation. Protein and Peptide Letters, 16(6), 598-605.

55. Newnam, G. P., Birchmore, J. L., \& Chernoff, Y. O. (2011). Destabilization and recovery of a yeast prion after mild heat shock. Journal of Molecular Biology, 408(3), 432-448.

56. Bueler, H., Fischer, M., Lang, Y., Bluethmann, H., Lipp, H. P., DeArmond, S. J., et al. (1992). Normal development and behaviour of mice lacking the neuronal cell-surface PrP protein. Nature, 356(6370), 577-582.

57. Bueler, H., Aguzzi, A., Sailer, A., Greiner, R. A., Autenried, P., Aguet, M., et al. (1993). Mice devoid of PrP are resistant to scrapie. Cell, 73(7), 1339-1347.

58. Bruce, K. L., \& Chernoff, Y. O. (2011). Sequence specificity and fidelity of prion transmission in yeast. Seminars in Cell and Developmental Biology, doi: 10.1016/j.semcdb.2011.03.005. (in press)

59. Lawson, V. A., Priola, S. A., Wehrly, K., \& Chesebro, B. (2001). N-terminal truncation of prion protein affects both formation and conformation of abnormal protease-resistant prion protein generated in vitro. Journal of Biological Chemistry, 276(38), 35265-35271. 
60. Moore, R. A., Herzog, C., Errett, J., Kocisko, D. A., Arnold, K. M., Hayes, S. F., et al. (2006). Octapeptide repeat insertions increase the rate of protease-resistant prion protein formation. Protein Science, 15(3), 609-619.

61. Parham, S. N., Resende, C. G., \& Tuite, M. F. (2001). Oligopeptide repeats in the yeast protein Sup35p stabilize intermolecular prion interactions. EMBO Journal, 20(9), 2111-2119.

62. Makarava, N., \& Baskakov, I. V. (2008). The same primary structure of the prion protein yields two distinct self-propagating states. Journal of Biological Chemistry, 283(23), 15988-15996.

63. Collinge, J., Sidle, K. C., Meads, J., Ironside, J., \& Hill, A. F. (1996). Molecular analysis of prion strain variation and the aetiology of 'new variant' CJD. Nature, 383(6602), 685-690.

64. Yap, Y. H., \& Say, Y. H. (2011). Resistance against apoptosis by the cellular prion protein is dependent on its glycosylation status in oral HSC-2 and colon LS 174T cancer cells. Cancer Letters, 306(1), 111-119.

65. Si, K., Choi, Y. B., White-Grindley, E., Majumdar, A., \& Kandel, E. R. (2010). Aplysia CPEB can form prion-like multimers in sensory neurons that contribute to long-term facilitation. Cell, 140(3), 421-435.

66. Si, K., Lindquist, S., \& Kandel, E. R. (2003). A neuronal isoform of the aplysia CPEB has prion-like properties. Cell, 115(7), 879-891.

67. Ter-Avanesyan, M., Derkatch, I., Baskakov, I., \& Kushnirov, V. (2005). Unraveling prion structures and biological functions. Genome Biology, 6(13), 366.

68. Heinrich, S. U., \& Lindquist, S. (2011). Protein-only mechanism induces self-perpetuating changes in the activity of neuronal Aplysia cytoplasmic polyadenylation element binding protein (CPEB). Proceedings of the National Academy of Sciences of the United States of America, 108(7), 2999-3004.

69. Burns, D. M., \& Richter, J. D. (2008). CPEB regulation of human cellular senescence, energy metabolism, and p53 mRNA translation. Genes and Development, 22(24), 3449-3460.

70. Burns, D. M., D'Ambrogio, A., Nottrott, S., \& Richter, J. D. (2011). CPEB and two poly(A) polymerases control miR-122 stability and p53 mRNA translation. Nature, 473(7345), 105108.

71. Kadnar, M. L. (2010). The complex prion domain of Rnq1 provides insight into transmission barriers and prion strain formation. Dissertation, New York University, New York, United States. http://proquest.umi.com/pqdlink?did=1981440581\&Fmt=7\&clientI $\mathrm{d}=79356 \& \mathrm{RQT}=309 \& \mathrm{VName}=\mathrm{PQD}$

72. Maddelein, M. L., \& Wickner, R. B. (1999). Two prion-inducing regions of Ure2p are nonoverlapping. Molecular and Cellular Biology, 19(6), 4516-4524.

73. Serio, T. R., \& Lindquist, S. L. (1999). [PSI+]: an epigenetic modulator of translation termination efficiency. Annual Review of Cell and Developmental Biology, 15, 661-703.

74. Michelitsch, M. D., \& Weissman, J. S. (2000). A census of glutamine/asparagine-rich regions: implications for their conserved function and the prediction of novel prions. Proceedings of the National Academy of Sciences of the United States of America, 97(22), 11910-11915.

75. Gabus, C., Derrington, E., Leblanc, P., Chnaiderman, J., Dormont, D., Swietnicki, W., et al. (2001). The prion protein has RNA binding and chaperoning properties characteristic of nucleocapsid protein NCP7 of HIV-1. Journal of Biological Chemistry, 276(22), 1930119309.

76. Deleault, N. R., Lucassen, R. W., \& Supattapone, S. (2003). RNA molecules stimulate prion protein conversion. Nature, 425(6959), 717-720.

77. Silva, J. L., Vieira, T. C., Gomes, M. P., Bom, A. P., Lima, L. M., Freitas, M. S., et al. (2010). Ligand binding and hydration in protein misfolding: insights from studies of prion and p53 tumor suppressor proteins. Accounts of Chemical Research, 43(2), 271-279.

78. Beaudoin, S., Vanderperre, B., Grenier, C., Tremblay, I., Leduc, F., \& Roucou, X. (2009). A large ribonucleoprotein particle induced by cytoplasmic PrP shares striking similarities with the chromatoid body, an RNA granule predicted to function in posttranscriptional gene regulation. Biochimica et Biophysica Acta, 1793(2), 335-345. 
79. Taneja, V., Maddelein, M. L., Talarek, N., Saupe, S. J., \& Liebman, S. W. (2007). A non-Q/Nrich prion domain of a foreign prion, [Het-s], can propagate as a prion in yeast. Molecular Cell, 27(1), 67-77.

80. Osherovich, L. Z., Cox, B. S., Tuite, M. F., \& Weissman, J. S. (2004). Dissection and design of yeast prions. PLoS Biology, 2(4), E86.

81. Cordeiro, Y., Kraineva, J., Gomes, M. P., Lopes, M. H., Martins, V. R., Lima, L. M., et al. (2005). The amino-terminal PrP domain is crucial to modulate prion misfolding and aggregation. Biophysical Journal, 89(4), 2667-2676.

82. Rogers, M., Yehiely, F., Scott, M., \& Prusiner, S. B. (1993). Conversion of truncated and elongated prion proteins into the scrapie isoform in cultured cells. Proceedings of the National Academy of Sciences of the United States of America, 90(8), 3182-3186.

83. Chernoff, Y. O., Lindquist, S. L., Ono, B., Inge-Vechtomov, S. G., \& Liebman, S. W. (1995). Role of the chaperone protein Hsp104 in propagation of the yeast prion-like factor [psi+]. Science, 268(5212), 880-884.

84. Sun, G., Guo, M., Shen, A., Mei, F., Peng, X., Gong, R., et al. (2005). Bovine PrPC directly interacts with alphaB-crystalline. FEBS Letters, 579(24), 5419-5424.

85. Jones, G. W., \& Tuite, M. F. (2005). Chaperoning prions: the cellular machinery for propagating an infectious protein? Bioessays, 27(8), 823-832, doi:10.1002/bies.20267.

86. Rekas, A., Adda, C. G., Aquilina, J. A., Barnham, K. J., Sunde, M., Galatis, D., et al. (2004). Interaction of the molecular chaperone alphaB-crystallin with alpha-synuclein: effects on amyloid fibril formation and chaperone activity. Journal of Molecular Biology, 340(5), 1167-1183.

87. Borchsenius, A. S., Muller, S., Newnam, G. P., Inge-Vechtomov, S. G., \& Chernoff, Y. O. (2006). Prion variant maintained only at high levels of the Hsp104 disaggregase. Current Genetics, 49(1), 21-29.

88. Borchsenius, A. S., Wegrzyn, R. D., Newnam, G. P., Inge-Vechtomov, S. G., \& Chernoff, Y. O. (2001). Yeast prion protein derivative defective in aggregate shearing and production of new 'seeds'. EMBO Journal, 20(23), 6683-6691.

89. Cox, B. S., Byrne, L. J., \& Tuite, M. F. (2007). Prion stability. Prion, 1(3), 170-178.

90. Tanaka, M., Collins, S. R., Toyama, B. H., \& Weissman, J. S. (2006). The physical basis of how prion conformations determine strain phenotypes. Nature, 442(7102), 585-589.

91. Bailleul, P. A., Newnam, G. P., Steenbergen, J. N., \& Chernoff, Y. O. (1999). Genetic study of interactions between the cytoskeletal assembly protein sla1 and prion-forming domain of the release factor Sup35 (eRF3) in Saccharomyces cerevisiae. Genetics, 153(1), 81-94.

92. Baron, G. S., Wehrly, K., Dorward, D. W., Chesebro, B., \& Caughey, B. (2002). Conversion of raft associated prion protein to the protease-resistant state requires insertion of PrP-res (PrP(Sc)) into contiguous membranes. EMBO Journal, 21(5), 1031-1040.

93. Chernova, T. A., Romanyuk, A. V., Karpova, T. S., Shanks, J. R., Ali, M., Moffatt, N., et al. (2011). Prion induction by the short-lived, stress-induced protein Lsb2 is regulated by ubiquitination and association with the actin cytoskeleton. Molecular Cell, 43(2), 242-252.

94. Ganusova, E. E., Ozolins, L. N., Bhagat, S., Newnam, G. P., Wegrzyn, R. D., Sherman, M. Y., et al. (2006). Modulation of prion formation, aggregation, and toxicity by the actin cytoskeleton in yeast. Molecular and Cellular Biology, 26(2), 617-629.

95. Shyng, S. L., Huber, M. T., \& Harris, D. A. (1993). A prion protein cycles between the cell surface and an endocytic compartment in cultured neuroblastoma cells. Journal of Biological Chemistry, 268(21), 15922-15928.

96. Tyedmers, J., Treusch, S., Dong, J., McCaffery, J. M., Bevis, B., \& Lindquist, S. (2010). Prion induction involves an ancient system for the sequestration of aggregated proteins and heritable changes in prion fragmentation. Proceedings of the National Academy of Sciences of the United States of America, 107(19), 8633-8638. 
97. Bailleul-Winslett, P. A., Newnam, G. P., Wegrzyn, R. D., \& Chernoff, Y. O. (2000). An antiprion effect of the anticytoskeletal drug latrunculin A in yeast. Gene Expression, 9(3), 145-156.

98. Olson, M. F., \& Sahai, E. (2009). The actin cytoskeleton in cancer cell motility. Clinical and Experimental Metastasis, 26(4), 273-287.

99. Liang, J., Pan, Y. L., Ning, X. X., Sun, L. J., Lan, M., Hong, L., et al. (2006). Overexpression of PrPC and its antiapoptosis function in gastric cancer. Tumour Biology, 27(2), 84-91.

100. Diarra-Mehrpour, M., Arrabal, S., Jalil, A., Pinson, X., Gaudin, C., Pietu, G., et al. (2004). Prion protein prevents human breast carcinoma cell line from tumor necrosis factor alphainduced cell death. Cancer Research, 64(2), 719-727.

101. Lang, G. I., \& Murray, A. W. (2008). Estimating the per-base-pair mutation rate in the yeast Saccharomyces cerevisiae. Genetics, 178(1), 67-82.

102. Fernandez-Bellot, E., Guillemet, E., \& Cullin, C. (2000). The yeast prion [URE3] can be greatly induced by a functional mutated URE2 allele. EMBO Journal, 19(13), 3215-3222.

103. Deng, M., Chen, P. C., Xie, S., Zhao, J., Gong, L., Liu, J., et al. (2010). The small heat shock protein alphaA-crystallin is expressed in pancreas and acts as a negative regulator of carcinogenesis. Biochimica et Biophysica Acta, 1802(7-8), 621-631.

104. Shyu, W. C., Harn, H. J., Saeki, K., Kubosaki, A., Matsumoto, Y., Onodera, T., et al. (2002). Molecular modulation of expression of prion protein by heat shock. Molecular Neurobiology, 26(1), 1-12.

105. Shyu, W. C., Kao, M. C., Chou, W. Y., Hsu, Y. D., \& Soong, B. W. (2000). Creutzfeldt-Jakob disease: heat shock protein 70 mRNA levels in mononuclear blood cells and clinical study. Journal of Neurology, 247(12), 929-934.

106. Liang, J., Pan, Y., Zhang, D., Guo, C., Shi, Y., Wang, J., et al. (2007). Cellular prion protein promotes proliferation and G1/S transition of human gastric cancer cells SGC7901 and AGS. FASEB Journal, 21(9), 2247-2256.

107. Fulda, S. (2009). Tumor resistance to apoptosis. International Journal of Cancer, 124(3), 511515.

108. Roucou, X., Giannopoulos, P. N., Zhang, Y., Jodoin, J., Goodyer, C. G., \& LeBlanc, A. (2005). Cellular prion protein inhibits proapoptotic Bax conformational change in human neurons and in breast carcinoma MCF-7 cells. Cell Death and Differentiation, 12(7), 783795.

109. Dewson, G., \& Kluck, R. M. (2009). Mechanisms by which Bak and Bax permeabilise mitochondria during apoptosis. Journal of Cell Science, 122(Pt 16), 2801-2808.

110. Kurschner, C., \& Morgan, J. I. (1995). The cellular prion protein (PrP) selectively binds to Bcl-2 in the yeast two-hybrid system. Brain Research. Molecular Brain Research, 30(1), 165-168.

111. Kurschner, C., \& Morgan, J. I. (1996). Analysis of interaction sites in homo- and heteromeric complexes containing Bcl-2 family members and the cellular prion protein. Brain Research. Molecular Brain Research, 37(1-2), 249-258.

112. Meslin, F., Hamai, A., Gao, P., Jalil, A., Cahuzac, N., Chouaib, S., et al. (2007). Silencing of prion protein sensitizes breast adriamycin-resistant carcinoma cells to TRAIL-mediated cell death. Cancer Research, 67(22), 10910-10919.

113. Mao, Y. W., Liu, J. P., Xiang, H., \& Li, D. W. (2004). Human alphaA- and alphaB-crystallins bind to Bax and $\mathrm{Bcl}-\mathrm{X}(\mathrm{S})$ to sequester their translocation during staurosporine-induced apoptosis. Cell Death and Differentiation, 11(5), 512-526.

114. Ashkenazi, A., \& Herbst, R. S. (2008). To kill a tumor cell: the potential of proapoptotic receptor agonists. Journal of Clinical Investigation, 118(6), 1979-1990.

115. Guillot-Sestier, M. V., Sunyach, C., Druon, C., Scarzello, S., \& Checler, F. (2009). The alphasecretase-derived $\mathrm{N}$-terminal product of cellular prion, N1, displays neuroprotective function in vitro and in vivo. Journal of Biological Chemistry, 284(51), 35973-35986. 
116. Kristiansen, M., Messenger, M. J., Klohn, P. C., Brandner, S., Wadsworth, J. D., Collinge, J., et al. (2005). Disease-related prion protein forms aggresomes in neuronal cells leading to caspase activation and apoptosis. Journal of Biological Chemistry, 280(46), 38851-38861.

117. Liang, J., Ge, F. L., Lu, Y. Y., Wang, J., Zhai, H. H., Yao, L. P., et al. (2006). Role of PrPc Related to Apoptosis. Experimental and Clinical Sciences International Journal, 5, 11-24.

118. Paitel, E., Alves da Costa, C., Vilette, D., Grassi, J., \& Checler, F. (2002). Overexpression of PrPc triggers caspase 3 activation: potentiation by proteasome inhibitors and blockade by anti-PrP antibodies. Journal of Neurochemistry, 83(5), 1208-1214.

119. Kamradt, M. C., Chen, F., \& Cryns, V. L. (2001). The small heat shock protein alpha Bcrystallin negatively regulates cytochrome c- and caspase-8-dependent activation of caspase-3 by inhibiting its autoproteolytic maturation. Journal of Biological Chemistry, 276(19), 16059-16063.

120. Hao, S., Ye, Z., Li, F., Meng, Q., Qureshi, M., Yang, J., et al. (2006). Epigenetic transfer of metastatic activity by uptake of highly metastatic B16 melanoma cell-released exosomes. Experimental Oncology, 28(2), 126-131.

121. Fevrier, B., Vilette, D., Laude, H., \& Raposo, G. (2005). Exosomes: a bubble ride for prions? Traffic, 6(1), 10-17.

122. Harris, J. F., Chambers, A. F., Hill, R. P., \& Ling, V. (1982). Metastatic variants are generated spontaneously at a high rate in mouse KHT tumor. Proceedings of the National Academy of Sciences of the United States of America, 79(18), 5547-5551.

123. Stackpole, C. W. (1983). Generation of phenotypic diversity in the B16 mouse melanoma relative to spontaneous metastasis. Cancer Research, 43(7), 3057-3065.

124. Schirrmacher, V. (1980). Shifts in tumor cell phenotypes induced by signals from the microenvironment. Relevance for the immunobiology of cancer metastasis. Immunobiology, 157(2), 89-98.

125. Allen, K. D., Chernova, T. A., Tennant, E. P., Wilkinson, K. D., \& Chernoff, Y. O. (2007). Effects of ubiquitin system alterations on the formation and loss of a yeast prion. Journal of Biological Chemistry, 282(5), 3004-3013.

126. Chernoff, Y. O., Newnam, G. P., Kumar, J., Allen, K., \& Zink, A. D. (1999). Evidence for a protein mutator in yeast: role of the Hsp70-related chaperone ssb in formation, stability, and toxicity of the [PSI] prion. Molecular and Cellular Biology, 19(12), 8103-8112.

127. Fidler, I. J. (1978). Tumor heterogeneity and the biology of cancer invasion and metastasis. Cancer Research, 38(9), 2651-2660.

128. Halfmann, R., Alberti, S., \& Lindquist, S. (2010). Prions, protein homeostasis, and phenotypic diversity. Trends in Cell Biology, 20(3), 125-133.

129. Pan, Y., Zhao, L., Liang, J., Liu, J., Shi, Y., Liu, N., et al. (2006). Cellular prion protein promotes invasion and metastasis of gastric cancer. FASEB Journal, 20(11), 1886-1888.

130. Liang, J., Ge, F., Guo, C., Luo, G., Wang, X., Han, G., et al. (2009). Inhibition of PI3K/Akt partially leads to the inhibition of $\operatorname{Pr} P(C)$-induced drug resistance in gastric cancer cells. FEBS Journal, 276(3), 685-694.

131. Harris, C. C. (1996). p53 tumor suppressor gene: from the basic research laboratory to the clinic--an abridged historical perspective. Carcinogenesis, 17(6), 1187-1198.

132. Hoh, J., Jin, S., Parrado, T., Edington, J., Levine, A. J., \& Ott, J. (2002). The p53MH algorithm and its application in detecting p53-responsive genes. Proceedings of the National Academy of Sciences of the United States of America, 99(13), 8467-8472.

133. Mirza, A., Wu, Q., Wang, L., McClanahan, T., Bishop, W. R., Gheyas, F., et al. (2003). Global transcriptional program of p53 target genes during the process of apoptosis and cell cycle progression. Oncogene, 22(23), 3645-3654.

134. Higashimoto, Y., Asanomi, Y., Takakusagi, S., Lewis, M. S., Uosaki, K., Durell, S. R., et al. (2006). Unfolding, aggregation, and amyloid formation by the tetramerization domain from mutant p53 associated with lung cancer. Biochemistry, 45(6), 1608-1619. 
135. Ishimaru, D., Andrade, L. R., Teixeira, L. S., Quesado, P. A., Maiolino, L. M., Lopez, P. M., et al. (2003). Fibrillar aggregates of the tumor suppressor p53 core domain. Biochemistry, 42(30), 9022-9027.

136. Lee, A. S., Galea, C., DiGiammarino, E. L., Jun, B., Murti, G., Ribeiro, R. C., et al. (2003). Reversible amyloid formation by the p53 tetramerization domain and a cancer-associated mutant. Journal of Molecular Biology, 327(3), 699-709.

137. Rigacci, S., Bucciantini, M., Relini, A., Pesce, A., Gliozzi, A., Berti, A., et al. (2008). The (1$63)$ region of the 553 transactivation domain aggregates in vitro into cytotoxic amyloid assemblies. Biophysical Journal, 94(9), 3635-3646.

138. Milner, J., \& Medcalf, E. A. (1991). Cotranslation of activated mutant p53 with wild type drives the wild-type p53 protein into the mutant conformation. Cell, 65(5), 765-774.

139. Muras, A. G., Hajj, G. N., Ribeiro, K. B., Nomizo, R., Nonogaki, S., Chammas, R., et al. (2009). Prion protein ablation increases cellular aggregation and embolization contributing to mechanisms of metastasis. International Journal of Cancer, 125(7), 1523-1531.

140. Collinge, J., Whitfield, J., McKintosh, E., Beck, J., Mead, S., Thomas, D. J., et al. (2006). Kuru in the 21st century - an acquired human prion disease with very long incubation periods. Lancet, 367(9528), 2068-2074.

141. McEwan, J. F., Windsor, M. L., \& Cullis-Hill, S. D. (2009). Antibodies to prion protein inhibit human colon cancer cell growth. Tumour Biology, 30(3), 141-147.

142. Cleary, J. M., \& Shapiro, G. I. (2010). Development of phosphoinositide-3 kinase pathway inhibitors for advanced cancer. Current Oncology Reports, 12(2), 87-94.

143. Shin, J. Y., Kim, J. O., Lee, S. K., Chae, H. S., \& Kang, J. H. (2010). LY294002 may overcome 5-FU resistance via down-regulation of activated p-AKT in Epstein-Barr viruspositive gastric cancer cells. BMC Cancer, 10, 425.

144. Ng, S. S. W., Tsao, M. S., Chow, S., \& Hedley, D. W. (2000). Inhibition of phosphatidylinositide 3-kinase enhances gemcitabine-induced apoptosis in human pancreatic cancer cells. Cancer Research, 60(19), 5451-5455.

145. Sun, Z. J., Chen, G., Hu, X., Zhang, W., Liu, Y., Zhu, L. X., et al. (2010). Activation of $\mathrm{PI3K} / \mathrm{Akt} / \mathrm{IKK}$-alpha/NF-kappaB signaling pathway is required for the apoptosis-evasion in human salivary adenoid cystic carcinoma: its inhibition by quercetin. Apoptosis, 15(7), 850863.

146. Wang, Y. A., Johnson, S. K., Brown, B. L., McCarragher, L. M., Al-Sakkaf, K., Royds, J. A., et al. (2008). Enhanced anti-cancer effect of a phosphatidylinositol-3 kinase inhibitor and doxorubicin on human breast epithelial cell lines with different p53 and oestrogen receptor status. International Journal of Cancer, 123(7), 1536-1544.

147. Liu, J. J., \& Duan, R. D. (2009). LY294002 enhances boswellic acid-induced apoptosis in colon cancer cells. Anticancer Research, 29(8), 2987-2991.

148. Mohapatra, S., Chu, B., Zhao, X., Djeu, J., Cheng, J. Q., \& Pledger, W. J. (2009). Apoptosis of metastatic prostate cancer cells by a combination of cyclin-dependent kinase and AKT inhibitors. International Journal of Biochemistry and Cell Biology, 41(3), 595-602.

149. Krammer, C., Kryndushkin, D., Suhre, M. H., Kremmer, E., Hofmann, A., Pfeifer, A., et al. (2009). The yeast Sup35NM domain propagates as a prion in mammalian cells. Proceedings of the National Academy of Sciences of the United States of America, 106(2), 462-467.

150. Bach, S., Talarek, N., Andrieu, T., Vierfond, J. M., Mettey, Y., Galons, H., et al. (2003). Isolation of drugs active against mammalian prions using a yeast-based screening assay. Nature Biotechnology, 21(9), 1075-1081.

151. Grimminger, V., Richter, K., Imhof, A., Buchner, J., \& Walter, S. (2004). The prion curing agent guanidinium chloride specifically inhibits ATP hydrolysis by Hsp104. Journal of Biological Chemistry, 279(9), 7378-7383.

152. Korth, C., May, B. C., Cohen, F. E., \& Prusiner, S. B. (2001). Acridine and phenothiazine derivatives as pharmacotherapeutics for prion disease. Proceedings of the National Academy of Sciences of the United States of America, 98(17), 9836-9841. 
153. Hildebrandt, B., Wust, P., Ahlers, O., Dieing, A., Sreenivasa, G., Kerner, T., et al. (2002). The cellular and molecular basis of hyperthermia. Critical Reviews in Oncology/Hematology, 43(1), 33-56.

154. Gottesman, M. M., \& Ling, V. (2006). The molecular basis of multidrug resistance in cancer: the early years of P-glycoprotein research. FEBS Letters, 580(4), 998-1009.

155. Li, Q. Q., Cao, X. X., Xu, J. D., Chen, Q., Wang, W. J., Tang, F., et al. (2009). The role of Pglycoprotein/cellular prion protein interaction in multidrug-resistant breast cancer cells treated with paclitaxel. Cellular and Molecular Life Sciences, 66(3), 504-515.

156. Hennequin, E., Delvincourt, C., Pourny, C., \& Jardillier, J. C. (1993). Expression of mdr1 gene in human breast primary tumors and metastases. Breast Cancer Research and Treatment, 26(3), 267-274.

157. Isonishi, S., Hom, D. K., Thiebaut, F. B., Mann, S. C., Andrews, P. A., Basu, A., et al. (1991). Expression of the c-Ha-ras oncogene in mouse NIH 3T3 cells induces resistance to cisplatin. Cancer Research, 51(21), 5903-5909.

158. Li, Q. Q., Wang, W. J., Xu, J. D., Cao, X. X., Chen, Q., Yang, J. M., et al. (2007). Upregulation of CD147 and matrix metalloproteinase-2, -9 induced by P-glycoprotein substrates in multidrug resistant breast cancer cells. Cancer Science, 98(11), 1767-1774.

159. Yang, J. M., Xu, Z., Wu, H., Zhu, H., Wu, X., \& Hait, W. N. (2003). Overexpression of extracellular matrix metalloproteinase inducer in multidrug resistant cancer cells. Molecular Cancer Research, 1(6), 420-427.

160. Shorter, J. (2010). Emergence and natural selection of drug-resistant prions. Molecular Biosystems, 6(7), 1115-1130.

161. Cooper, M., \& Mishima, Y. (1972). Increased in vitro radio-sensitivity of malignant melanoma induced by the in vivo administration of chlorpromazine. British Journal of Dermatology, 86(5), 491-494.

162. Yde, C. W., Clausen, M. P., Bennetzen, M. V., Lykkesfeldt, A. E., Mouritsen, O. G., \& Guerra, B. (2009). The antipsychotic drug chlorpromazine enhances the cytotoxic effect of tamoxifen in tamoxifen-sensitive and tamoxifen-resistant human breast cancer cells. AntiCancer Drugs, 20(8), 723-735.

163. Gao, J. M., Zhou, X. B., Xiao, X. L., Zhang, J., Chen, L., Gao, C., et al. (2006). Influence of guanidine on proteinase $\mathrm{K}$ resistance in vitro and infectivity of scrapie prion protein $\operatorname{PrP}(\mathrm{Sc})$. Acta Virologica, 50(1), 25-32.

164. Callahan, M. A., Xiong, L., \& Caughey, B. (2001). Reversibility of scrapie-associated prion protein aggregation. Journal of Biological Chemistry, 276(30), 28022-28028.

165. Armitage, P., \& Doll, R. (1954). The age distribution of cancer and a multi-stage theory of carcinogenesis. British Journal of Cancer, 8(1), 1-12.

166. Frank, S. A. (2005). Age-specific incidence of inherited versus sporadic cancers: a test of the multistage theory of carcinogenesis. Proceedings of the National Academy of Sciences of the United States of America, 102(4), 1071-1075. 